Illinois State University

ISU ReD: Research and eData

Theses and Dissertations

$5-14-2014$

\title{
Equality of Opportunity: The Relationship between Tracking and Educational Outcomes
}

Chris Colgren

Illinois State University, ccolgren@sps186.org

Follow this and additional works at: https://ir.library.illinoisstate.edu/etd

Part of the Education Commons

\section{Recommended Citation}

Colgren, Chris, "Equality of Opportunity: The Relationship between Tracking and Educational Outcomes" (2014). Theses and Dissertations. 190.

https://ir.library.illinoisstate.edu/etd/190

This Dissertation is brought to you for free and open access by ISU ReD: Research and eData. It has been accepted for inclusion in Theses and Dissertations by an authorized administrator of ISU ReD: Research and eData. For more information, please contact ISUReD@ilstu.edu. 


\title{
EQUALITY OF OPPORTUNITY: THE RELATIONSHIP BETWEEN TRACKING AND EDUCATIONAL OUTCOMES
}

\author{
Christopher C. Colgren
}

116 Pages

August 2014

To explore tracking policies and practices in relation to achievement equity, this quantitative study examined the relationship and differences between students who have completed Advanced Placement (AP)/Honors courses and those who have not in traditional Illinois public high schools. Using a cross-sectional survey design, the study used secondary data from the Illinois State Board of Education indicating high school students' socioeconomic status, race, placement in AP/Honors courses, and ACT scores to answer five research questions that reflected a general understanding of tracking policies and practices as currently employed in American public schools. Specifically, the study addressed the following questions:

1. What are the differences in ACT scores between students who have completed at least one $\mathrm{AP} /$ Honors (English, mathematics, science, and/or social studies) course and those who have not?

2. What are the differences in ACT scores between (a) Black students and White students who have completed at least one AP/Honors (English, mathematics, science, and/or social studies) course when income is accounted for, (b) Latino students and White students who have completed at least one 
AP/Honors (English, mathematics, science, and/or social studies) course when income is accounted for, and (c) Black and Latino students who have completed at least one AP/Honors (English, mathematics, science, and/or social studies) course when income is accounted for?

3. What are the differences in ACT scores between (a) Black students who have completed at least one AP/Honors (English, mathematics, science, and/or social studies) course and those who have not, (b) Latino students who have completed at least one AP/Honors (English, mathematics, science, and/or social studies) course and those who have not, and (c) White students who have completed at least one AP/Honors (English, mathematics, science, and/or social studies) course and those who have not?

4. What are the differences in ACT scores between low-income students and non low-income students who have completed at least one AP/Honors (English, mathematics, science, and/or social studies) course?

5. What are the differences in ACT scores between (a) low-income students who have completed at least one AP/Honors (English, mathematics, science, and/or social studies) course and those who have not, and (b) non low-income students who have completed at least one AP/Honors (English, mathematics, science, and/or social studies) course and those who have not?

To analyze the data, the statistical technique called analysis of variance was used in combination with post hoc tests. Data analysis indicated that across all content areas studied (English, mathematics, science, social studies/reading), students who participated in $\mathrm{AP} /$ Honors courses performed significantly better on $\mathrm{ACT}$ tests than students who 
completed only lower track classes. These performance increases were evident regardless of students' socioeconomic status or race. Furthermore, effect sizes generally indicated medium to large treatment effects when comparing the ACT performance of students who completed at least one AP/Honors course to that of students who did not.

The findings of this study suggest that in the interest of increasing student achievement, the elimination of tracking policies and practices would be advantageous to all students. Simply increasing access to the most rigorous curricular and instructional offerings will not, however, result in a narrowing of achievement gaps based upon socioeconomic status and race. While this study found that all students who participated in $\mathrm{AP} /$ Honors courses performed better academically than similar peers who participated in only lower track courses, mean differences indicated that some student groups benefited more from participation in high-track courses than others. Specifically, non low-income students derived a greater benefit from participation in $\mathrm{AP} /$ Honors courses than low-income students. And White students experienced a greater benefit from participating in $\mathrm{AP} /$ Honors courses than African American and Latino students. Therefore, in order to simultaneously increase academic achievement while pursuing achievement equity, detracking must be approached as a means of transforming the traditional practices of schooling so that all students receive access to a rigorous curriculum and uniform quality of instruction that reflect the cultural inclinations of a pluralistic society. 


\title{
EQUALITY OF OPPORTUNITY: THE RELATIONSHIP BETWEEN
}

TRACKING AND EDUCATIONAL OUTCOMES

CHRISTOPHER C. COLGREN

\author{
A Dissertation Submitted in Partial \\ Fulfillment of the Requirements \\ for the Degree of \\ DOCTOR OF PHILOSOPHY \\ Department of Educational Administration and Foundations \\ ILLINOIS STATE UNIVERSITY




\section{EQUALITY OF OPPORTUNITY: THE RELATIONSHIP BETWEEN}

TRACKING AND EDUCATIONAL OUTCOMES

CHRISTOPHER C. COLGREN

COMMITTEE MEMBERS:

Neil Sappington, Chair

John Rugutt

Elizabeth Lugg

Guy Banicki 


\section{ACKNOWLEDGMENTS}

I am grateful to all who have encouraged and supported me throughout this process. To my colleagues, I thank you for providing the motivation and inspiration needed to further my research and advance my ideas in the field. I appreciate the dedication of the educators whom I have worked with throughout my career. Your commitment to the students we have collectively served has inspired me to make achievement equity a reality for all children. I am especially grateful to those who collaborated with me in pursuit of this degree. To my classmates and mentors, I could not have completed the journey without you.

To my professors at the University of Illinois at Springfield and Illinois State University, I thank you for relentlessly challenging me to learn and accomplish more. Your courses have helped shape me as an educator and researcher. In particular, I wish to acknowledge my entire dissertation committee for their willingness to share their knowledge and expertise. I am especially grateful for the direction and support that my Dissertation Chairperson, Dr. Neil Sappington, provided throughout the arduous task of completing my research. Similarly, I feel forever indebted to my methodologist, Dr. John Rugutt, for sharing his expertise in quantitative research.

I would be remiss if I did not also thank my parents, John and Mary, for their unwavering support throughout my life and career. After all, it was my parents who taught me life's most important lessons. The values you have inculcated in me have shaped who I am as an individual and, for that, I am forever grateful. 
Finally, I wish to thank my wife, Kristin. Your patience and encouragement over the years allowed me to stay focused on my dreams and goals. Thank you for keeping me motivated in the good times and reassuring me through life's challenges. Thank you for always believing in me. I would not be where I am today, nor would I be who I am today, if not for you and our son, Cameron.

C.C.C. 


\section{CONTENTS}

Page

ACKNOWLEDGMENTS

CONTENTS

TABLES

CHAPTER

i

iii

$\mathrm{V}$
Background 3

Statement of the Problem 4

$\begin{array}{ll}\text { Theoretical Perspective } & 6\end{array}$

Purpose of the Study $\quad 8$

$\begin{array}{lr}\text { Research Questions } & 10\end{array}$

Definition of Terms 11

Assumptions and Limitations of the Study 11

$\begin{array}{ll}\text { Overview of the Study } & 12\end{array}$

II. REVIEW OF THE LITERATURE 13

A Need for Equality of Opportunity in Contemporary Education 13

The Achievement Gap $\quad 13$

A Shift in Demographics $\quad 22$

The Transition to a Knowledge-Based Society 24

Foundations of American Public Schooling 26

A System Designed for an Industrial Society 26

$\begin{array}{ll}\text { The School as a Factory } & 27\end{array}$

Industrial Age Assumptions About Learning and Schooling $\quad 30$

Historical Origins of Tracking 35

The Unintended Consequences of Tracking Practices 41

The Success of Detracking 46

Summary $\quad 49$ 
III. METHODOLOGY 51

Research Design $\quad 51$

$\begin{array}{ll}\text { The Population and Sample } & 52\end{array}$

Instrumentation $\quad 53$

Variables in the Study $\quad 55$

Data Analysis and Interpretation $\quad 56$

Internal and External Validity $\quad 57$

$\begin{array}{ll}\text { Summary } & 58\end{array}$

IV. ANALYSIS OF THE DATA 59

Descriptive Statistics $\quad 60$

Research Question $1 \quad 63$

Research Question $2 \quad 66$

Research Question $3 \quad 76$

Research Question $4 \quad 85$

Research Question 5 89

$\begin{array}{ll}\text { Summary } & 95\end{array}$

V. FINDINGS, IMPLICATIONS, AND CONCLUSIONS 96

Discussion of Findings $\quad 97$

$\begin{array}{lr}\text { Implications for Further Research } & 102\end{array}$

Summary and Conclusions 104

$\begin{array}{ll}\text { REFERENCES } & 110\end{array}$ 


\section{TABLES}

Table

Page

1. Nine-Year-Old Reading Achievement (NAEP Long-Term Trend Data) 15

2. Thirteen-Year-Old Reading Achievement (NAEP Long-Term Trend Data) 15

3. Seventeen-Year-Old Reading Achievement (NAEP Long-Term Trend Data) 16

4. Nine-Year-Old Mathematics Achievement (NAEP Long-Term Trend Data) 17

5. Thirteen-Year-Old Mathematics Achievement (NAEP Long-Term Trend Data)

6. Seventeen-Year-Old Mathematics Achievement (NAEP) Long-Term Trend Data)

7. Grade 4 Reading Achievement (NAEP Main Data) 19

8. Grade 8 Reading Achievement (NAEP Main Data) 20

9. Grade 12 Reading Achievement (NAEP Main Data) 20

10. Grade 4 Mathematics Achievement (NAEP Main Data) 21

11. Grade 8 Mathematics Achievement (NAEP Main Data) 21

12. Grade 12 Mathematics Achievement (NAEP Main Data) 21

13. Differences in Students' ACT Mean Scores by Content Area 64

14. ANOVA Summary Table 64

15. Differences in Non Low-Income ACT Mean Scores by Race 67

16. Differences in Low-Income ACT Mean Scores by Race 68

17. Differences in Black Students' ACT Mean Scores by Content Area 77 
18. Differences Between Black Students Who Completed at Least

One AP/Honors Course and Those Who Did Not

19. Differences in Latino Students' ACT Mean Scores by Content Area

20. Differences Between Latino Students Who Completed at Least

One AP/Honors Course and Those Who Did Not

21. Differences in White Students' ACT Mean Scores by Content Area

22. Differences Between White Students Who Completed at Least

One AP/Honors Course and Those Who Did Not

23. Differences Between Low-Income and Non Low-Income Students'

ACT Mean Scores by Content Area

24. Differences Between Low-Income and Non Low-Income Students' Who Completed at Least One AP/Honors Course

25. Differences in Low-Income Students' ACT Mean Scores by Content Area

26. Differences Between Low-Income Students Who Completed at Least One AP/Honors Course and Those Who Did Not

27. Differences in Non Low-Income Students' ACT Mean Scores by Content Area

28. Differences Between Non Low-Income Students Who Completed at Least One AP/Honors Course and Those Who Did Not

29. Mean Differences Between Students Who Participated in AP/Honors Courses and Those Who Did Not (Compared by Race)

30. Mean Differences Between Students Who Participated in AP/Honors Courses and Those Who Did Not (Compared by Socioeconomic Status) 


\section{CHAPTER I}

\section{INTRODUCTION TO THE STUDY}

The education that children receive in $21^{\text {st }}$ century America remains influenced by a system of public schooling established long ago during an era of rapid industrialization. Around the turn of the $20^{\text {th }}$ century, as manufacturing gained prominence in a predominantly agrarian society, political, economic, social, and intellectual factors were suddenly being shaped by principles of mass production, standardization, and efficiency. Consequently, the foundation for public education was heavily influenced by Industrial Age assumptions about learning and schooling. Over 100 years later, the policies and practices that developed as American schooling was conceptualized have remained embedded in the traditional structure of contemporary education-arguably to the detriment of many children (Callahan, 1962).

As the nation transformed from an industry- to knowledge-based society around the turn of the $21^{\text {st }}$ century, America's societal and economic needs were once again significantly altered (Thrilling \& Fadel, 2009). As a result of widespread technological changes and increased globalization, educators, policymakers, and members of the public began calling for education reform in an effort to meet the demands of a knowledgebased society. Many of these reformers consider persistent gaps in academic achievement between various student groups to be the most pressing and perplexing problem facing $21^{\text {st }}$ century education (Boykin \& Noguera, 2011; Muhammad, 2009; 
Wagner, 2008). Students' socioeconomic status (Anyon, 2005; Rothstein, 2004; Wilson, 2009; White, 1982; Siren, 2005), cultural environment (Howard, 2010; Kunjufu, 1995; 2002), and family background (Jencks, Smith, Aclanand, Bane, Cohen, Gintis, Heyns, \& Michelson, 1972; Jencks \& Phillips, 1998) have been studied alongside school-related factors, including tracking (Oakes, 2005; Burris \& Welner, 2005; Oakes, Garomen, \& Page, 1992; Wells \& Oakes, 1996), to explain achievement gaps.

Issues of achievement disparities generated even greater attention as the result of Federal legislation and initiatives aimed at standards-based education reform. For example, the mandates of the No Child Left Behind (NCLB) Act require that all students meet high learning standards and that gaps in academic achievement between racial and ethnic groups disappear (NCLB Act of 2001, 2008). Furthermore, the implementation of the Common Core State Standards Initiative ensures that all students, no matter where they live, are well prepared with the skills and knowledge necessary to collaborate and compete with their peers in the United States and abroad. According to the United States Department of Education (USDE), "Every student should graduate from high school ready for college and a career, regardless of their income, race, ethnic or language background, or disability status" (USDE, 2010, p. 3).

Passage of the NCLB Act and implementation of the Common Core State Standards have prompted many educators to question the policies and practices of traditional American schooling. Increased performance expectations and more rigorous standards have added emphasis to earlier criticisms that the American education system was never designed to educate all students to achieve high levels of proficiency (Elmore, 2002). In reality, the American system of schooling assumes that the success of some 
children is dependent on the failure of others (Schlechty, 2009). But as educators, policy makers, and members of the public recognize that variances in academic abilities cannot be attributed to race, poverty, or other genetic or cultural factors, attention will continue to shift to school-related factors in order to explain gaps in academic achievement. In fact, the "achievement gap" that has generated so much attention in contemporary American public education is perhaps more accurately depicted as an opportunity gap (Boykin \& Noguera, 2011; Darling-Hammond, 2010).

As an increasing number of schools across the nation face sanctions for failing to meet the provisions of standards-based reform measures, the unintended consequences of maintaining Industrial Age assumptions about learning and schooling are becoming strikingly apparent. Among the most notable barriers to making achievement equity a reality for all children is the nearly ubiquitous practice of separating students for instruction based upon achievement or ability (Oakes, 2005). Commonly referred to as tracking, the sorting of students into classes at different levels based upon judgments of students' perceived ability levels does not align with the goals of a standards-based educational system with a commitment to leaving no child behind.

\section{Background}

The historical origins of tracking systems in the United States trace back to the early 1900s when American schools were enrolling growing numbers of immigrant children as the result of compulsory schooling laws. During this period, it was widely assumed that intelligence was fixed and measurable. Accordingly, educational reformers of the time, many who believed in differential intelligence, adopted tracking as a means of sorting immigrant children viewed as having limited preparation or capacity for 
schooling from native children. Students were formally assigned to academic, general, or vocational tracks based upon socioeconomic status. In this way, schools became mechanisms for the efficient sorting of manpower in an industrialized economy (Oakes, 2005).

Initially, tracking systems were developed to satisfy the needs of an economy based upon a large unskilled labor force. Over time, the rigid tracking systems were dismantled in the United States and replaced with somewhat less rigid tracking systems characterized by curriculum differentiation. In modern tracking systems, students are assigned to different levels of the same course, or to a course with a different curriculum that is either more or less rigorous (Burris \& Garrity, 2008; Lucas, 1999; Yonezawa, Wells, \& Serna, 2002). Often referred to as "ability-grouping" in an attempt to avoid the stigma of tracking, modern systems result in de facto tracking and provide for a continuance of the unequal and ineffective practices of old-fashioned tracking systems (Lucas, 1999; Yonezawa, Wells, \& Serna, 2002). Specifically, students assigned to lowtrack classes experience curriculum and instructional differences that dramatically restrict their knowledge and opportunities to learn (Oakes \& Wells, 1998; Darling-Hammond, 2010; Eckstrom \& Villages, 1991; Garoman, 1998; Oakes, 2005). Despite such findings, the practice of tracking has become so institutionalized that the traditional public school system has been referred to as a system of sorting (Oakes, 2005; DuFour \& Eaker, 1998; Muhammad, 2009).

\section{Statement of the Problem}

The consequences of outdated educational policies and practices have resulted in a system of schooling that has not proven effective for all children. This problem is 
perhaps most visible as a result of achievement disparities across racial and socioeconomic backgrounds (Boykin \& Noguera, 2011; Howard, 2010; DarlingHammond, 2010; Muhammad, 2009; Wagner, 2008). For example, data from the National Assessment of Educational Progress (NAEP), a congressionally mandated measure of student achievement that has been administered by the National Center for Educational Statistics since 1969, indicates striking gaps in academic achievement between Black and Latino students and their White counterparts. A gap is similarly witnessed between students, regardless of race, who come from low-income backgrounds and their peers who come from middle-class or affluent backgrounds (Howard, 2010). Data on SAT performance from the College Board also reveals gaps in academic achievement based on race and socioeconomic status (Howard, 2010). Concurrent research on tracking indicates that minority and low-income students are statistically underrepresented in high-track classes and overrepresented in low-track classes (Dornbusch, 1994; Oakes, 2005; Oakes, Garoman, \& Page, 1992; Burris \& Welner, 2005; Wells \& Serna, 1996; Yonezawa, Wells, \& Serna, 2002).

In response to discrepancies in educational outcomes, the Department of Education aims to ensure all students are capable of thriving in a global, knowledgeeconomy by promoting college and career success. According to President Obama, "We must do better....We must raise the expectations for our students, for our schools, and for ourselves.... We must ensure that every student graduates from high school well prepared for college and a career" (USDE, 2010, p. 1). Satisfying such ambitious goals will require critical examination of all barriers to students' academic success. Burris and Welner (2005) assert, “Achievement follows from opportunities... and the persistent 
practice of tracking denies a range of opportunities to large numbers of students" (p. 594). With a quality education serving as an avenue to remaining competitive in a knowledge-based society, now is not the time to limit opportunities. Yet, at a time in which schools must ensure all students are ready for college and career, tracking systems remain a major barrier to achievement equity. This study explored the effects of tracking policies and practices on educational outcomes by examining the relationship and differences between students who have completed AP/Honors courses and those who have not in traditional Illinois public high schools.

\section{Theoretical Perspective}

In research, a theory is an interrelated set of constructs formed into propositions that specify the relationship among variables (Creswell, 2009). When approached deductively, the theory becomes a framework for the entire study. This postpositivist study is shaped by the theoretical perspective that equality in meaningful educational opportunities results in achievement equity. While equality of opportunity reflects the American spirit, embracing equity in educational outcomes presents a paradigm shift for most Americans, including contemporary educators, who have been conditioned to view academic ability as unevenly distributed in the population. The assumption that high intelligence is possessed by a relatively small percentage of people has generated considerable attention as a result of the "bell curve" (Boykin \& Noguera, 2011). Creating a system of schooling in which all students perform at high levels, however, necessitates replacing the traditional bell curve with a model of universal student achievement.

Providing every child with equal educational opportunities, including exposure to a rigorous curriculum and uniform quality of instruction, will theoretically improve 
educational outcomes for all students. Marzano (2000) identified "opportunity to learn" as the school-level factor with the strongest relationship to student achievement. Boykin and Noguera (2011) argue that closing the achievement gap is a matter of creating the “opportunity to learn” for all children. As supported in the research and literature, providing students with equal opportunities to learn requires educators to maintain the expectation that "all students can progress, that achievement for all is changeable (and not fixed), and that progress for all is understood and articulated" (Hattie, 2009, p. 35). In simple terms, high levels of academic achievement follow from meaningful educational opportunities.

The theoretical perspective shaping this study, therefore, aligns with the universal development thesis, which suggests that all normally functioning humans have the capacity to reason sufficiently well to finish high school and enter college when they are supported with the appropriate academic and social scaffolds (Bruner, 1986; Cicourel \& Mehan, 1985; Meier, 1995; Resnick, 1995). Furthermore, the theory acknowledges Robert Merton's idea of the "self-fulfilling prophecy," a notion initially popularized in sociology. Subsequent research in the field of education revealed that having low expectations of students' success leads to poor academic performance (Hattie, 2009; Senge, Cambron-McCabe, Lucas, Smith, Dutton, \& Kleiner, 2012). Conversely, expecting students to master challenging content through quality instruction contributes to their academic success (Hattie, 2009). As demonstrated through the "Pygmalion effect," labeling students shaped their academic performance, which in turn reinforced the labels (Senge et al., 2012). 
Rooted in Industrial Age assumptions about learning and schooling, tracking policies and practices label students and, thus, contribute to the inequalities that continue to marginalize many students, particularly low-income and minority children, in contemporary American schools (Darling-Hammond, 2010). Much has changed in the world since the ratification of compulsory education laws and the simultaneous adoption of tracking policies and practices in schools. During a period in which industrialization created a need for large quantities of unskilled laborers alongside a managerial class capable of operating the factories and businesses, sorting students into groups based upon academic ability levels seemed logical. Rapidly evolving technologies and rise of globalization that have characterized the $21^{\text {st }}$ century, however, have produced a shift from an industry-based economy to a knowledge-based economy. The political, social, and economic changes that accompany this transition place increased value on achievement equity (Friedman, 2007; Darling-Hammond, 2010; Wagner, 2008; Trilling \& Fadel, 2009). And in order for children to achieve their full potential, they must logically receive the opportunity to do so.

\section{Purpose of the Study}

The purpose of this study was to examine the relationship and differences between students who have completed Advanced Placement (AP)/Honors courses and those who have not in traditional Illinois public high schools. The independent variables examined include income, race, and AP/Honors placement. For the purposes of this study, income was defined by either participation or non-participation in the National School Lunch Program. Specifically, students who participated in the National School Lunch Program were considered low-income, whereas, students who did not participate 
in the National School Lunch Program were considered non low-income. Race was defined through three groups: Black students, Latino students, and White students. Information regarding race was reported by individual schools and districts based upon a system of self-reporting. AP/Honors courses were defined as accelerated courses offered in place of basic courses required for credit in the following subject areas: English, mathematics, science, and social studies. For a high school course to have the AP designation, the course must be audited by the College Board to ascertain it satisfies the AP curriculum. If the course is approved, the school may use the AP designation and the course is publicly listed on the AP Ledger. The dependent variable was standardized test scores as reported by ACT in the following content areas: English, mathematics, reading, and science. The ACT college readiness assessment is a curriculum- and standards-based educational and career planning tool that accesses students' academic readiness for college (ACT, 2013).

Despite an increased need for college and career ready students, tracking policies and practices continue to pose barriers to achievement equity (Burris \& Welner, 2005; Oakes, 2005; Oakes et al., 1992; Wells \& Oakes, 1996). Educational tracking as it currently exists in schools appears contradictory to the goals of standards-based education reform as well as the demands of a knowledge-based economy. The results of this study, therefore, contribute to understanding the role of education in the $21^{\text {st }}$ century. Findings may also contribute to the closing of achievement gaps identified by socioeconomic status and race, and potentially lead to increased high school graduation and college enrollment rates. Accordingly, the results are of practical significance to 
researchers and practitioners interested in achieving equality of opportunities in public education.

\section{Research Questions}

The research questions for this study reflect a general understanding of tracking policies and practices as currently employed in American public schools. In this study, the following research questions were explored:

1. What are the differences in ACT scores between students who have completed at least one AP/Honors (English, mathematics, science, and/or social studies) course and those who have not?

2. What are the differences in ACT scores between (a) Black students and White students who have completed at least one AP/Honors (English, mathematics, science, and/or social studies) course when income is accounted for, (b) Latino students and White students who have completed at least one AP/Honors (English, mathematics, science, and/or social studies) course when income is accounted for, and (c) Black and Latino students who have completed at least one AP/Honors (English, mathematics, science, and/or social studies) course when income is accounted for?

3. What are the differences in ACT scores between (a) Black students who have completed at least one AP/Honors (English, mathematics, science, and/or social studies) course and those who have not, (b) Latino students who have completed at least one AP/Honors (English, mathematics, science, and/or social studies) course and those who have not, and (c) White students who have completed at least one AP/Honors (English, mathematics, science, and/or social studies) course and those who have not?

4. What are the differences in ACT scores between low-income students and non low-income students who have completed at least one AP/Honors (English, mathematics, science, and/or social studies) course?

5. What are the differences in ACT scores between (a) low-income students who have completed at least one AP/Honors (English, mathematics, science, and/or social studies) course and those who have not, and (b) non low-income students who have completed at least one AP/Honors (English, mathematics, science, and/or social studies) course and those who have not? 


\section{Definition of Terms}

Achievement Gap - the difference in academic performance between two groups of students.

AP/Honors Courses - accelerated courses offered in place of basic courses. required for credit in the following subject areas: English, mathematics, science, and social studies.

Income-participation or non-participation in the National School Lunch Program.

Low-Income — students eligible to participate in the National School Lunch Program.

Non Low-Income - students not eligible to participate in the National School Lunch Program.

Tracking — the offering of leveled courses characterized by varying degrees of curricular rigor.

\section{Assumptions and Limitations of the Study}

The following assumptions were applied to this study:

1. All information regarding socioeconomic status and race was accurately reported by students and families to schools and districts.

2. All information regarding socioeconomic status, race, AP/Honors placement, and ACT performance was accurately reported by schools and districts to the Illinois State Board of Education.

3. AP/Honors course placement affords students more rigorous curricular exposure than comparably offered courses within the same school or district. 
The following limitations were applied to the study:

1. This study was limited to schools and districts within the state of Illinois.

2. Data analyzed for this study reflects only the 2012-2013 school year.

3. This study did not attempt to determine students', parents', educators', or any other stakeholders' perceptions of tracking policies and practices.

\section{Overview of the Study}

This study is organized into five chapters. Chapter II contains a review of the literature on tracking policies and practices. The literature review begins at the turn of the $20^{\mathrm{t}}$ century and explores the theoretical and structural organization of schools during a period dominated by factories and assembly lines. The origins of tracking policies and practices are discussed in relation to Industrial Age assumptions regarding learning and schooling that have endured through time. Finally, as America transitioned from an industry-based to a knowledge-based economy, the consequences of sorting students are explored.

Chapter III provides the methodology for this study. The purpose of the research is presented in detail, as well as, the procedures for data collection and analysis. Chapter IV follows with a presentation of the data in relation to the research questions. Chapter V concludes by discussing the findings of this study as well as the implications of the research. Conclusions are drawn with the intent of making achievement equity a reality for all children. 


\section{CHAPTER II}

\section{REVIEW OF THE LITERATURE}

\section{A Need for Equality of Opportunity in Contemporary Education \\ The Achievement Gap}

In contemporary American public education, not all students are achieving at high

levels. Furthermore, a convergence of $21^{\text {st }}$ century political, social, and economic factors contributed to a heightened sense of urgency to improve the educational outcomes of underperforming students. With achievement data indicating disparities across racial and socioeconomic backgrounds, federal mandates compelled schools to provide greater attention to the educational needs of poor and disadvantaged children; students with learning disabilities; recent immigrants and English language learners; and African Americans, Latinos, Native Americans, and other students of color (Boykin \& Noguera, 2011). Many of the recent school reform measures have been initiated in response to what is commonly referred to as the "achievement gap."

If schools are to truly match the rhetoric of contemporary educators and policymakers, they must begin to create equal opportunities for all children to learn. Sadly, this is not the current reality among the majority of schools in the $21^{\text {st }}$ century. Moreover, since the inception of American public education, this has not been a reality. Schools were never designed to educate the majority of students at high levels (Elmore, 2002), and thus, too many educators have been conditioned to believe that not all students 
are capable of achieving the levels of proficiency mandated under the No Child Left Behind (NCLB) Act or desired through the implementation of the Common Core State Standards.

Logically, unequal access to education leads to unequal levels of achievement. Within the past few decades, discrepancies in educational outcomes between various student groups has generated so much attention that the term "achievement gap" is recognized as perhaps the single most pressing and perplexing issue in education thus far in the $21^{\text {st }}$ century (Howard, 2010). Over the past 30 years, National Assessment of Educational Progress (NAEP) data demonstrated test score disparities across racial and socioeconomic backgrounds over the full range of academic skills and content areas.

Because student achievement is enhanced when students have strong literacy and reading backgrounds, reading is arguably the most important subject area for academic success (Howard, 2010). While the NAEP long-term trend assessment scores in reading among 9- through 17-year-old students, displayed in Tables 1 through 3, demonstrate that achievement of Black and Latino students has risen over the past few decades, these gains have not necessarily translated to the narrowing of the Black/White or Latino/White achievement gaps. Corresponding increases in White student achievement have contributed to continued discrepancies in educational outcomes among ethnically diverse student populations. 
Table 1

Nine-Year-Old Reading Achievement (NAEP Long-Term Trend Data)

\begin{tabular}{ccccccc}
\hline & \multicolumn{3}{c}{ Average Scale Score } & & \multicolumn{2}{c}{ Achievement Gap } \\
\cline { 2 - 3 } \cline { 6 - 7 } Year & White & Black & Latino & & Black/White & Latino/White \\
\hline 2012 & 229 & 206 & 208 & & -23 & -21 \\
2008 & 228 & 204 & 207 & & -24 & -21 \\
2004 & 224 & 197 & 199 & & -27 & -25 \\
1999 & 221 & 186 & 193 & & -35 & -28 \\
1996 & 220 & 191 & 195 & & -29 & -25 \\
1994 & 218 & 185 & 186 & & -33 & -32 \\
1992 & 218 & 185 & 192 & & -33 & -26 \\
1990 & 217 & 182 & 189 & & -35 & -28 \\
1988 & 218 & 189 & 194 & & -29 & -24 \\
1984 & 218 & 186 & 187 & & -32 & -31 \\
1980 & 221 & 189 & 190 & -32 & -31 \\
\hline
\end{tabular}

Table 2

Thirteen-Year-Old Reading Achievement (NAEP Long-Term Trend Data)

\begin{tabular}{ccccccc}
\hline & \multicolumn{3}{c}{ Average Scale Score } & & \multicolumn{2}{c}{ Achievement Gap } \\
\cline { 2 - 3 } \cline { 6 - 7 } Year & White & Black & Latino & & Black/White & Latino/White \\
\hline 2012 & 270 & 247 & 249 & & -23 & -21 \\
2008 & 268 & 247 & 242 & & -21 & -26 \\
2004 & 265 & 239 & 241 & & -25 & -24 \\
1999 & 267 & 238 & 244 & & -29 & -23 \\
1996 & 266 & 234 & 238 & & -32 & -28 \\
1994 & 265 & 234 & 235 & & -31 & -30 \\
1992 & 266 & 234 & 235 & & -29 & -27 \\
1990 & 262 & 241 & 238 & & -21 & -24 \\
1988 & 261 & 243 & 240 & & -18 & -21 \\
1984 & 263 & 236 & 240 & & -26 & -23 \\
1980 & 264 & 233 & 237 & -32 & -27 \\
\hline
\end{tabular}


Table 3

Seventeen-Year-Old Reading Achievement (NAEP Long-Term Trend Data)

\begin{tabular}{ccccccc}
\hline & \multicolumn{3}{c}{ Average Scale Score } & & \multicolumn{2}{c}{ Achievement Gap } \\
\cline { 7 - 7 } \cline { 6 - 7 } Year & White & Black & Latino & & Black/White & Latino/White \\
\hline 2012 & 295 & 269 & 274 & & -26 & -21 \\
2008 & 295 & 266 & 269 & & -29 & -26 \\
2004 & 289 & 262 & 267 & & -27 & -22 \\
1999 & 295 & 264 & 271 & & -31 & -24 \\
1996 & 295 & 266 & 265 & & -29 & -30 \\
1994 & 296 & 266 & 263 & & -30 & -33 \\
1992 & 297 & 261 & 271 & & -36 & -26 \\
1990 & 297 & 267 & 275 & & -30 & -22 \\
1988 & 295 & 274 & 271 & & -21 & -24 \\
1984 & 295 & 264 & 268 & & -31 & -27 \\
1980 & 293 & 243 & 261 & -50 & -32 \\
\hline
\end{tabular}

Achievement in mathematics, a content area often serving as a gatekeeper for post-secondary educational access (Conley, 2007), demonstrates a similar trend to reading performance. As shown in Tables 4 through 6, the Black/White achievement gap for 9- through 17-year-old students has persisted since the late 1970s. Similarly, the Latino/White achievement gap for 9- through 17-year-old students has remained consistent over time.

Thus, despite gains in reading and mathematics achievement among Black and Latino students, NAEP data suggests that the Black/White and Latino/White achievement gaps have remained stagnant for more than 20 years (Boykin \& Noguera, 2011). In addition to reading and mathematics achievement, NEAP data reveal similar discrepancies in the areas of science, writing, and citizenship (Howard, 2010). 
Table 4

Nine-Year-Old Mathematics Achievement (NAEP Long-Term Trend Data)

\begin{tabular}{ccccccc}
\hline & \multicolumn{3}{c}{ Average Scale Score } & & \multicolumn{2}{c}{ Achievement Gap } \\
\cline { 2 - 3 } \cline { 6 - 7 } Year & White & Black & Latino & & Black/White & Latino/White \\
\hline 2012 & 252 & 226 & 234 & & -26 & -18 \\
2008 & 250 & 224 & 234 & & -26 & -16 \\
2004 & 245 & 221 & 229 & & -24 & -16 \\
1999 & 239 & 211 & 213 & & -28 & -26 \\
1996 & 237 & 212 & 215 & & -28 & -26 \\
1994 & 237 & 212 & 210 & & -25 & -22 \\
1992 & 235 & 208 & 212 & & -27 & -23 \\
1990 & 235 & 208 & 214 & & -27 & -21 \\
1986 & 227 & 202 & 205 & & -25 & -21 \\
1982 & 224 & 195 & 204 & -29 & -20 \\
1978 & 224 & 192 & 203 & -32 & -21 \\
\hline
\end{tabular}

Table 5

Thirteen-Year-Old Mathematics Achievement (NAEP Long-Term Trend Data)

\begin{tabular}{ccccccc}
\hline & \multicolumn{3}{c}{ Average Scale Score } & & \multicolumn{2}{c}{ Achievement Gap } \\
\cline { 2 - 3 } \cline { 6 - 7 } Year & White & Black & Latino & & Black/White & Latino/White \\
\hline 2012 & 293 & 264 & 271 & & -29 & -22 \\
2008 & 290 & 262 & 268 & & -28 & -23 \\
2004 & 287 & 257 & 264 & & -30 & -23 \\
1999 & 283 & 251 & 259 & & -32 & -24 \\
1996 & 281 & 252 & 256 & & -29 & -25 \\
1994 & 281 & 252 & 256 & & -29 & -25 \\
1992 & 279 & 250 & 259 & & -29 & -20 \\
1990 & 276 & 249 & 255 & & -27 & -22 \\
1986 & 274 & 249 & 254 & & -24 & -19 \\
1982 & 274 & 240 & 252 & & -34 & -22 \\
1978 & 272 & 230 & 238 & -42 & -34 \\
\hline
\end{tabular}


Table 6

Seventeen-Year-Old Mathematics Achievement (NAEP Long-Term Trend Data)

\begin{tabular}{ccccccc}
\hline & \multicolumn{3}{c}{ Average Scale Score } & & \multicolumn{2}{c}{ Achievement Gap } \\
\cline { 2 - 3 } \cline { 6 - 7 } Year & White & Black & Latino & & Black/White & Latino/White \\
\hline 2012 & 314 & 288 & 294 & & -26 & -20 \\
2008 & 314 & 287 & 293 & & -27 & -21 \\
2004 & 311 & 284 & 292 & & -27 & -19 \\
1999 & 315 & 283 & 293 & & -32 & -22 \\
1996 & 313 & 286 & 292 & & -27 & -21 \\
1994 & 312 & 286 & 291 & & -26 & -20 \\
1992 & 312 & 286 & 292 & & -26 & -19 \\
1990 & 309 & 289 & 284 & & -20 & -25 \\
1986 & 308 & 279 & 283 & & -29 & -25 \\
1982 & 304 & 272 & 277 & & -32 & -27 \\
1978 & 306 & 268 & 276 & -38 & -30 \\
\hline
\end{tabular}

Along with race, poverty represents a significant risk factor in the pursuit of making achievement equity a reality for all children. There is undoubtedly a correlation between socioeconomic status and school outcomes (Howard, 2010), and students from low-income families, regardless of their racial group, are experiencing the costs of inferior educational opportunities (Edmonds, 1979). Students of poverty achieve at lower levels and have much lower graduation rates than the national average (Muhammad, 2009).

In contemporary education, the socioeconomic achievement gap appears in many ways to be more persistent than the race achievement gap. For example, the average achievement difference between a child from a family at the $90^{\text {th }}$ percentile of the family income distribution and a child from a family at the $10^{\text {th }}$ percentile in the $21^{\text {st }}$ century was nearly twice as large as the Black/White achievement gap. Fifty years ago, the 
Black/White achievement gap was larger than this socioeconomic achievement gap (Reardon, 2011). Furthermore, the difference in academic achievement between students from families at the $90^{\text {th }}$ percentile of the family income distribution and students from families at the $10^{\text {th }}$ percentile is approximately $30 \%$ to $40 \%$ larger among children born in 2001 than among those born 25 years earlier (Reardon, 2011).

In regards to poverty, NAEP data also demonstrates stagnant gaps in academic achievement in both reading and mathematics between students who qualify for the National School Lunch Program based upon household income and those who do not qualify. Tables 7 through 9, displaying reading scores of fourth- through twelfth-grade children, demonstrate a gap in the academic achievement of students of low-income households and their peers of middle-class or affluent homes. As indicated by the NAEP data, the low-income/non low-income achievement gap has remained virtually unchanged over time.

Table 7

Grade 4 Reading Achievement (NAEP Main Data)

\begin{tabular}{cccc}
\hline & \multicolumn{2}{c}{ Average Scale Score } & Achievement Gap \\
\cline { 2 - 4 } Year & $\begin{array}{c}\text { Eligible for National } \\
\text { School Lunch Program }\end{array}$ & $\begin{array}{c}\text { Not Eligible for National } \\
\text { School Lunch Program }\end{array}$ & $\begin{array}{c}\text { Low-Income/ } \\
\text { Non Low-Income }\end{array}$ \\
\hline 2011 & 207 & 235 & -28 \\
2009 & 206 & 232 & -26 \\
2007 & 205 & 232 & -27 \\
2005 & 203 & 230 & -27 \\
2003 & 201 & 229 & -28 \\
2002 & 203 & 230 & -27 \\
2000 & 193 & 226 & -33 \\
1998 & 196 & 227 & -31 \\
\hline
\end{tabular}


Table 8

Grade 8 Reading Achievement (NAEP Main Data)

\begin{tabular}{|c|c|c|c|}
\hline \multirow[b]{2}{*}{ Year } & \multicolumn{2}{|c|}{ Average Scale Score } & \multirow{2}{*}{$\begin{array}{l}\frac{\text { Achievement Gap }}{\text { Low-Income/ }} \\
\text { Non Low-Income }\end{array}$} \\
\hline & $\begin{array}{c}\text { Eligible for National } \\
\text { School Lunch Program }\end{array}$ & $\begin{array}{l}\text { Not Eligible for National } \\
\text { School Lunch Program }\end{array}$ & \\
\hline 2011 & 252 & 275 & -23 \\
\hline 2009 & 249 & 273 & -24 \\
\hline 2007 & 247 & 271 & -24 \\
\hline 2005 & 247 & 270 & -23 \\
\hline 2003 & 247 & 271 & -24 \\
\hline 2002 & 249 & 272 & -23 \\
\hline 1998 & 245 & 269 & -24 \\
\hline
\end{tabular}

Table 9

Grade 12 Reading Achievement (NAEP Main Data)

\begin{tabular}{|c|c|c|c|}
\hline \multirow[b]{2}{*}{ Year } & \multicolumn{2}{|c|}{ Average Scale Score } & \multirow{2}{*}{$\begin{array}{l}\text { Achievement Gap } \\
\text { Low-Income/ } \\
\text { Non Low-Income }\end{array}$} \\
\hline & $\begin{array}{l}\text { Eligible for National } \\
\text { School Lunch Program }\end{array}$ & $\begin{array}{l}\text { Not Eligible for National } \\
\text { School Lunch Program }\end{array}$ & \\
\hline 2009 & 273 & 294 & -21 \\
\hline 2005 & 271 & 290 & -19 \\
\hline 2002 & 273 & 289 & -16 \\
\hline 1998 & 270 & 293 & -23 \\
\hline
\end{tabular}

Similar to reading achievement trends, a significant achievement gap based on socioeconomic status is visible in terms of mathematics achievement among fourththrough twelfth-grade students. Again, this gap, portrayed in Tables 10 through 12 , remains virtually identical to where it stood in the mid-1990s. 
Table 10

Grade 4 Mathematics Achievement (NAEP Main Data)

\begin{tabular}{|c|c|c|c|}
\hline \multirow[b]{2}{*}{ Year } & \multicolumn{2}{|c|}{ Average Scale Score } & \multirow{2}{*}{$\begin{array}{l}\text { Achievement Gap } \\
\text { Low-Income/ } \\
\text { Non Low-Income }\end{array}$} \\
\hline & $\begin{array}{c}\text { Eligible for National } \\
\text { School Lunch Program }\end{array}$ & $\begin{array}{l}\text { Not Eligible for National } \\
\text { School Lunch Program }\end{array}$ & \\
\hline 2011 & 229 & 252 & -23 \\
\hline 2009 & 227 & 250 & -23 \\
\hline 2007 & 227 & 249 & -22 \\
\hline 2005 & 225 & 248 & -23 \\
\hline 2003 & 222 & 244 & -22 \\
\hline 2000 & 208 & 235 & -27 \\
\hline 1996 & 207 & 232 & -25 \\
\hline
\end{tabular}

Table 11

Grade 8 Mathematics Achievement (NAEP Main Data)

\begin{tabular}{|c|c|c|c|}
\hline \multirow[b]{2}{*}{ Year } & \multicolumn{2}{|c|}{ Average Scale Score } & \multirow{2}{*}{$\begin{array}{l}\text { Achievement Gap } \\
\text { Low-Income/ } \\
\text { Non Low-Income }\end{array}$} \\
\hline & $\begin{array}{c}\text { Eligible for National } \\
\text { School Lunch Program }\end{array}$ & $\begin{array}{l}\text { Not Eligible for National } \\
\text { School Lunch Program }\end{array}$ & \\
\hline 2009 & 269 & 296 & -27 \\
\hline 2009 & 266 & 294 & -28 \\
\hline 2007 & 265 & 291 & -26 \\
\hline 2005 & 262 & 288 & -26 \\
\hline 2003 & 259 & 287 & -28 \\
\hline 2000 & 253 & 283 & -30 \\
\hline 1996 & 250 & 277 & -27 \\
\hline
\end{tabular}

Table 12

Grade 12 Mathematics Achievement (NAEP Main Data)

\begin{tabular}{|c|c|c|c|}
\hline \multirow[b]{2}{*}{ Year } & \multicolumn{2}{|c|}{ Average Scale Score } & \multirow{2}{*}{$\begin{array}{l}\text { Achievement Gap } \\
\text { Low-Income/ } \\
\text { Non Low-Income }\end{array}$} \\
\hline & $\begin{array}{c}\text { Eligible for National } \\
\text { School Lunch Program }\end{array}$ & $\begin{array}{l}\text { Not Eligible for National } \\
\text { School Lunch Program }\end{array}$ & \\
\hline 2009 & 137 & 160 & -23 \\
\hline 2005 & 266 & 294 & -28 \\
\hline 2000 & 279 & 304 & -25 \\
\hline 1996 & 280 & 306 & -26 \\
\hline
\end{tabular}


NAEP data shared in the tables above provides compelling evidence of unequal educational outcomes between various student groups. In addition to the achievement

data shared, gaps are also visible among students of different cultural and socioeconomic backgrounds in regards to grades, graduation rates, and suspension and expulsion rates (Howard, 2010). While the gaps in academic achievement between Black and Latino students and their White peers, as well as, the gap between poor children and middleclass and affluent children have existed for the better part of the past two centuries (Reardon, 2011), attention to academic achievement gaps has increased within recent decades. Despite this increased awareness, however, achievement gaps remain virtually unchanged over the past 30 years (Howard, 2010; Boykin \& Noguera, 2011). The stagnant nature of these gaps in academic achievement is particularly problematic amid changing demographics in $21^{\text {st }}$ century America.

\section{A Shift in Demographics}

According to Howard (2010), "If current achievement gaps continue over the next several decades, an increasing proportion of the nation's citizens will be severely undereducated and ill prepared to compete in a global economy" (pp. 35-36). This assertion is based upon rapid changes in the ethnic and racial landscape of the United States that have occurred over the past century and will continue into the $21^{\text {st }}$ century. While the actual number of White U.S. citizens has increased substantially since the turn of the $20^{\text {th }}$ century, the percentage of White U.S. citizens has declined. According to the 1900 Census, White citizens made up $88 \%$ of the nation's total population. Just over a century later, that percentage had dipped to $65 \%$. In 1900, one out of every eight U.S. citizens was non-White, but by 2006 , one out of every three U.S. citizens was non-White 
(Howard, 2010). These dramatic demographic changes are the result of rapid ethnic and racial transformation that has occurred during the past three decades. For example, the Latino population in the United States has more than tripled in past 30 years. Between 1980 and 2005, the Latino population grew 192\%, from 14.6 million to 42.7 million. During the same time period, the Black population grew $39 \%$, from 26.1 million to 36.3 million, while the White population grew only 10\% (Howard, 2010).

Furthermore, experts anticipate similar population trends to continue over the next several decades. According to the Pew Research Center (PRC), by the year 2050, nearly one in five Americans will be an immigrant. Some demographers project that by 2050 , non-Whites will make up almost 50\% of the nation's population, placing the United States close to becoming a nation comprising mostly of non-Whites (Howard, 2010). These predictions center on current U.S. Census data demonstrating that Whites have a higher median age and lower reproduction rate than other ethnic groups, including Latinos and Blacks. Such numbers suggest further increases in the number of nonWhites in the United States, while the number of White Americans continues to decline (Howard, 2010).

The demographic changes occurring in the United States will understandably impact the nation's schools. In 1970, non-White students represented $20 \%$ of the U.S. student population. By 2007 , that number had grown to $42 \%$, and demographers project that by 2035 , non-White students will constitute a majority of the student population in the United States. This is already a reality a number of metropolitan cities throughout the country where the numbers of non-White students exceed the numbers of White students. In fact, in many cities, such as New York, Los Angeles, Chicago, Philadelphia, Houston, 
Detroit, Boston, Columbus, Fort Lauderdale, and Washington, D.C., non-White students represent an overwhelming majority of the student population (Howard, 2010).

\section{The Transition to a Knowledge-Based Society}

Alongside changing demographics, the United States has experienced recent social and economic changes that will continue well into the $21^{\text {st }}$ century. In 1991 , the total dollar amount spent on Industrial Age goods in the United States - engines and machines for agriculture, mining, construction, manufacturing, transportation, energy production, and so on-was exceeded for the first time in history by the amount spent on information and communications technologies - computers, servers, printers, software, phones, networking devices and systems, and the like (Thrilling \& Fadel, 2009). The transition from industry- to knowledge-based economy has significantly altered the nation's societal and economic needs.

In an effort to create the highly-skilled, well-educated workforce necessary to sustain a knowledge-based economy, more Americans must be prepared for postsecondary access and success. This is demonstrated by the increase in the number of jobs that require a college degree or where a college education is an advantage. Specifically, an estimated $85 \%$ of current jobs and $90 \%$ of the fastest-growing and best-paying jobs now require postsecondary education (Wagner, 2008).

Despite this need, currently, only 70\% America's students graduate from high school on time, a mere third graduate ready for college, and it is estimated that one out of every two students who start college never complete any kind of postsecondary degree. Sadly, these rates are even lower for poor and minority students (Wagner, 2008). Only six in ten children from low-income families graduate from high school, only one in three 
will enroll in college, and only one in seven will earn a bachelor's degree (Conley, 2007). While $80 \%$ of White and Asian students will earn a high school diploma, only $55 \%$ of Black and Latino students will complete high school (Levin \& Rouse, 2011).

For the United States to remain competitive in a global, knowledge-based economy, schools must prepare all students for college and career success (Burris \& Garrity, 2008; Darling-Hammond, 2010). For children to develop into productive and successful citizens in a knowledge-based society, they must be afforded exposure to a rigorous curriculum and uniform quality of instruction throughout schooling. Continued failure to provide all students with equitable educational opportunities will not satisfy the demands of a knowledge-based society or provisions of contemporary education reform efforts. These concerns are validated by the results of the most recent international assessments conducted by the Program in International Student Assessment (PISA).

The PISA is an international study launched in 1997 by the Organization for Economic Cooperation and Development (OECD) to evaluate educational systems worldwide. Since the year 2000, the PISA has tested the skills and knowledge of randomly-selected groups of 15-year-old students in more than 70 countries and economies. In 2012, the PISA focused on mathematics and included an optional computer-based assessment of mathematics and reading involving some 30 countries worldwide (OECD, 2013).

According to the PISA results, the United States ranked $21^{\text {st }}$ of 30 countries in the OECD in science, and $25^{\text {th }}$ of 30 countries in mathematics. Educational inequality significantly influenced the United States' performance with African American and Latino students scoring so far below the OECD average that the national average 
plummeted to the bottom tier of the rankings despite the fact that White and Asian students in the United States scored above the OECD average. Furthermore, of nations participating in the PISA, the United States is among those where two students of different socioeconomic backgrounds have the largest difference in expected scores (Darling-Hammond, 2010). Such disparities in scoring have prompted several education reformers to question an unjust system of sorting that continues to exclude some students from the full benefit of schooling (Darling-Hammond, 2010; Oakes, 2005; Boykin \& Noguera, 2009; Burris \& Garrity, 2008).

In fact, Darling-Hammond (2010) points out that in American public schools, far more than those in high-achieving nations around the world, unequal access to knowledge occurs very early in a child's schooling as the result of different programmatic and course-taking opportunities available to different students. Nevertheless, the century-old practice of sorting students based upon Industrial Age assumptions of learning and schooling continues despite an obvious need for education to keep pace with rapidly evolving societal and economic changes and $21^{\text {st }}$ century education goals.

\section{Foundations of American Public Schooling}

\section{A System Designed for an Industrial Society}

At the turn of the $20^{\text {th }}$ century, Harvard University President Charles Eliot held to the notion that from common and equal educational experiences would come an intelligent citizenry (Oakes, 2005). According to Eliot:

It is a curious fact, that we Americans habitually underestimate the capacity of pupils at almost every stage of education from the primary school through the university....It seems to me probable that the proportion of grammar school children incapable of pursuing geometry, algebra, and a foreign language would turn out to be much smaller than we now imagine. (Eliot, 1898, pp. 260-261) 
During the time in which the system of American public schooling was born, however, Eliot's beliefs were overshadowed by the political, economic, social, and intellectual factors of the Industrial Age. Consequently, many of the features of $21^{\text {st }}$ century schools were formed during a period of urbanization and industrialization in the early twentieth century. Indeed, the favored model of instruction in public schools has been heavily influenced by the principles of scientific management, a theory originally popularized in industry (Goodman, Shannon, Freeman, \& Murphy, 1987). Similarly, many enduring school practices, such as tracking, were based upon ideas that guided the development of the American system of manufacturing. The cumulative effect of a schooling system designed to satisfy the needs of an industry-based economy has led many contemporary educators to demand school transformation during the $21^{\text {st }}$ century.

This call for change has been exacerbated by the enactment of the No Child Left Behind (NCLB) Act, implementation of the Common Core State Standards Initiative, and need to satisfy the demands of a knowledge-based society. Industrial Age schools operating as rigid bureaucracies will not effectively address the need for equality and excellence in contemporary education. Rather, schools must begin to operate as learning organizations in which all students have access to a rigorous curriculum and uniform quality of instruction (Schlechty, 2009). To achieve this end, educators must be prepared to confront barriers to educational equity and efficacy in a knowledge-based society, including tracking policies and practices.

\section{The School as a Factory}

During the early $20^{\text {th }}$ century, the basic structure of the American school system was formed on the basis of several assumptions: "that behavior can be predicted; that 
intelligence is fixed and innate; that differences in intelligence can be accurately measured; and that based on these measurements, learning 'treatments' can be prescribed" (Lambert, Walker, Zimmerman, Cooper, Lambert, Gardner, \& Szabo, 2002, p. 16). These assumptions shaped schools into mechanisms for efficient sorting of manpower in the industrialized economy of the 1900s. According to educator W. B. Pillsbury in 1921:

We can picture the educational system as having a very important function as a selecting agency, a means of selecting the men of best intelligence from the deficient and mediocre. All are poured into the system at the bottom; the incapable are soon rejected and drop out after repeating various grades and pass into the ranks of unskilled labor.... The more intelligent who are to be clerical workers pass into high school; the most intelligent enter the universities whence they are selected for the professions. (Pillsbury, 1921, p. 71)

The metaphor of the school as a factory that guided the design of the American education system in the early twentieth century remains recognizable over a hundred years later.

When the school is seen as a factory it is reasoned that the organization's function is to distribute talent and develop a productive workforce. Consequently, the school's primary goal is to provide operating processes that ensure uniformity and enforcement of product standards set by businesses and universities. In the case of education, students are the products and the school's core business becomes one of shaping, molding, testing, sorting, and reporting (Schlechty, 2009).

During a period of industrial prominence, schools began the process of sorting students based upon perceived academic ability levels and differentiated the curriculum in an effort to mold students to meet the needs of the business community and higher education. Students were formally assigned to academic, general, or vocational tracks and educated separately. In doing so, tracking systems satisfied the needs of an economy 
based upon a large unskilled labor force. Since the early 1900s, however, expectations in society and the labor market have changed dramatically. While tracking policies have evolved in the United States since the turn of $20^{\text {th }}$ century, these changes have not maintained pace with societal and economic changes (Darling-Hammond, 2010; Kelly, McCain, \& Jukes, 2009; Trilling \& Fadel, 2009).

The transition from an industry- to knowledge-based economy has led to a significant decrease in available manufacturing jobs (Trilling \& Fadel, 2009). Furthermore, the pace and nature of technological progress in the $21^{\text {st }}$ century has made educating all children more critical than ever (Muhammad, 2009; Levin \& Rouse, 2011). With highly-skilled, well-educated workers serving as a basis for economic growth in a knowledge-based economy, schools need to do a far better job of educating poor and minority students (Boykin \& Noguera, 2011; Levin \& Rouse, 2011). Muhammad (2009) articulates a strong need for achieving equality and excellence in $21^{\text {st }}$ century education:

If the United States is to maintain its position in the world, the quality of education and academic skills of its students must improve. In addition, more students - not just white, middle-class, and affluent students - have to develop academically so that America can continue to compete and be a viable force in our new global economy. (p. 8)

The transition to knowledge-based society has also placed increased emphasis on attaining a college education. This is evidenced by an increasing number of jobs that require a college degree or where a college education is an advantage. In 1973, people with a high school education or less made up $72 \%$ of the nation's workforce. An economy dominated by manufacturing allowed those with less education but a strong work ethic to earn a middle-class wage, as $60 \%$ of high school graduates did. In effect, a high school diploma was an avenue to prosperity for millions of Americans during the 
Industrial Age (Symonds, Schwartz, \& Ferguson, 2011).

The net job growth in America over the past third of a century, however, has been generated by positions that require at least some post-secondary education. With $85 \%$ of current jobs and $90 \%$ of the fastest-growing and best-paying jobs requiring postsecondary education (Wagner, 2008), schooling beyond high school has become increasingly necessary in a knowledge-based society (Symonds, Schwartz, \& Ferguson, 2011).

Despite the demands of an economy shaped by information, knowledge, and innovation, schools continue to operate more like factories than learning organizations. Senge (1990) believes learning organizations will excel in the future as a result of their collaborative nature. Likening the concept to a "great team," Senge argues that learning organizations are possible because it is human nature to love to learn. He continues:

Most of us at one time or another have been part of a great "team," a group of people who functioned together in an extraordinary way-who trusted one another, who complemented each others' strengths and compensated for each others' limitations, who had common goals that were larger than individual goals, and who produced extraordinary results.... The team that became great didn't start off great - it learned how to produce extraordinary results. (p. 14)

Transforming traditional schools into learning organizations necessitates altering the beliefs, values, and meanings maintained since the inception of American public schooling. In other words, Industrial Age assumptions about learning and schooling must be challenged and the culture of education must evolve to no longer metaphorically associate schools with factories.

\section{Industrial Age Assumptions About Learning and Schooling}

The Industrial Age system of schooling developed into one of strict bureaucratic control in search of educational efficiency and productivity. Efforts to design instruction 
scientifically led to assumptions about both learning and schooling that, in many respects, remain prominent in contemporary education. Such assumptions developed in large part as a result of the compatibility between behavioral psychology and the principles of scientific management (Schlechty, 2009).

Popularized during the $20^{\text {th }}$ century by B. F. Skinner, behaviorism is largely concerned with the extent to which human phenomena can be measured and predicted. Behavioral theories contributed to many of the assumptions of learning during the Industrial Age. One of these assumptions, based upon the theory that behavior could be shaped and controlled, was the idea that children were in need of shaping (Senge et al., 2012). Cubberly's depiction of schools as factories captures the notion of shaping children remarkably well: "Schools are in a sense factories in which the raw materials (children) are to be shaped and fashioned into products to meet the various demands of life" (Cubberly, 1916, p. 338). With learning viewed as a means of shaping children into educated final products, it came to be further assumed that all children should learn in the same way. To this end, instruction is more likely to be standardized and, thus, emphasize rote memorization of discrete knowledge. The perceived role of the student is illustrated in the writings of Bobbitt: "The ability to add at a speed of 65 combinations per minute, with an accuracy of 94 percent is as definite a specification as can be set up for any aspect of the work of the steel plant" (quoted in Callahan, 1962, p. 81).

Much like factory work, Skinner (1968) suggested that to teach a skill, one must clearly specify the performance task the student is to learn and, then, break down the task into small achievable steps, from simple to complex. As the student performs each step, the teacher's role is to reinforce correct actions and make the necessary adjustments so 
that the student is always successful until the goal is finally achieved. Following successful completion, the teacher should use intermittent reinforcement to maintain the student's performance.

Consistent with accepted thought, it was further assumed that learning was an entirely intellectual affair (Senge et al., 2012). When learning is separated from action, students become the passive recipients of knowledge. Within this teacher-centric culture, instructional strategies focus upon whole-group instruction, lecture, and drill-and-practice (Lambert et al., 2002).

The influences of Skinnerian learning theory remain highly visible in contemporary American classrooms. For example, large concepts are still broken down into discrete skills. Teachers, then, rely on whole class instruction to teach the component parts in isolation, utilizing strategies such as drill-and-practice. Student behavior is shaped through the use of rewards and punishment. And, as indicated by the high-stakes testing movement, schools remain dependent on standardized measures of achievement, which align with behavioral approaches to learning (Lambert et al., 2002). Above all else, however, behavioral learning theory propagated a view of intelligence as innate and unchanging, which resulted in the assumption that some children were "smart" and others were "dumb" (Senge et al., 2012; Schlechty, 2009).

These assumptions of learning, based largely upon behaviorism, combined with assumptions about schooling, which developed in accordance with the principles of scientific management. During the "Age of Efficiency," Frederick Winslow Taylor introduced the theory of scientific management as a method to improve workers' productivity in order to increase industrialists' profits. To achieve this end, scientific 
management required the analysis of the labor of the most able worker in an attempt to standardize this practice for all workers. The process by which scientific management was to be employed can be described as follows:

To begin, the able worker's procedure was analyzed for its discrete parts; then each part was timed in order to eliminate nonessential movements, and finally these streamlined parts were reassembled into a series of activities performed by groups of workers. These new procedures were learned in a step-by-step fashion, each worker practicing his part while being timed, while financial incentives were offered to employees who performed their tasks according to these administrative plans. (Goodman et al., 1987, pp. 13-14)

The application of Taylor's ideas to Industrial Age innovations led to a period of mass production marked by unprecedented reliability and efficiency (Senge et al., 2012). Most notable of these innovations was, of course, the assembly line.

As scientific management gained public attention outside of the business world, including the endorsement of President Theodore Roosevelt, its influence began to spread beyond factories (Callahan, 1962). Education reformers relied upon Taylor's principles to create a model of school that was oriented to producing a standardized product as efficiently as possible. The end result was a school system fashioned in the image of the assembly line within an industrial factory.

The system was organized in discrete stages, called grades, which separated children by age in a manner similar to the way that industrial products were grouped according to their stage of completion. Students were expected to move from each grade to next with one another under the direction of teachers. In this way, teachers resembled local supervisors in charge of a particular stage of production. Within each grade, classes of 20 to 40 students met for specified periods in a scheduled day to drill for tests. The rigid time schedules, which relied on bells to separate periods of instruction, allowed the 
entire school to run at a uniform speed. Teachers were provided direction from administration as to what knowledge had to be covered at each grade level for the whole "line" to keep moving (Senge et al., 2012).

In accordance with the principles of scientific management, schools were organized as systems to maintain control over all aspects of educational processteachers control the students, administrators control the teachers, and school boards control the administrators. This system of fragmented specialization meshed well with the assumption that knowledge is inherently fragmented. In schools, knowledge was to be presented in discrete categories. Subjects, such as literature, mathematics, science, and history, were all viewed as distinct from one another. Within each of these fields, schools communicated knowledge as truth (Senge et al., 2012). In other words, the teacher possessed all the knowledge, which was shared with students through recitation (Lambert et al., 2002). Students, in turn, competed to determine who would acquire the most knowledge through memorization. And as a result, both inside and outside of the classroom, collaboration was virtually nonexistent (Senge et al., 2012).

The system of schooling described above remains apparent in American contemporary public education. It should, therefore, come as no surprise that the Industrial Age assumptions of learning and schooling that forged traditional schools remain deeply entrenched in the hearts and minds of many $21^{\text {st }}$ century educators. Accordingly, the influences of behavioral psychology and scientific management are highly visible in contemporary education policies and practices, as evidenced by the continued prominence of tracking in American schools. 


\section{Historical Origins of Tracking}

Industrial Age assumptions about learning and schooling became the justification for labeling and sorting students within the context of American public schooling. More than 100 years later, tracking remains so recognizable in contemporary education that the American public school system is frequently described as a system of sorting children (Oakes, 2005; DuFour \& Eaker, 1998; Muhammad, 2009).

Tracking is the process of sorting students into categories so that they can be assigned in groups to various kinds of classes. Students may be sorted on the basis of their scores on achievement or ability tests, teachers' perceptions of what students have already learned or their potential for learning, or what seems most appropriate for their future lives. In some schools, students are classified and placed separately for each academic subject. For example, a student may be placed in a high-track reading class and a low-track math class. In other schools, a single decision determines a student's program for the entire day, semester, or year (Oakes, 2005; Burris \& Garrity, 2008; Darling-Hammond, 2010). However students are sorted, research demonstrates that tracking practices and policies result in unintended consequences that do not align with the equity-minded goals of achieving standards-based education reform in a knowledgebased society (Darling-Hammond, 2010; Burris \& Garrity, 2008).

To understand why schools continue to sort students in the $21^{\text {st }}$ century, it is important to examine the historical and social context of tracking. Like all reform initiatives, tracking originated as a solution to a specific set of educational and social problems at a particular time in history. The development tracking in American schools can be traced back over 100 years ago to a period in which industrial efficiency reigned 
supreme (Oakes, 2005; Darling-Hammond, 2010).

Following the development of the public high school during the latter part of the $19^{\text {th }}$ century came the first push for schools to help sort and select students for higher education as well as prepare them for it. In 1892, the Committee of Ten on Secondary Studies of the National Education Association was established to standardize secondary schools' college-preparatory curricula and colleges' admission requirements. At the same time that the committee was postulating on education reform, the country was experiencing a population explosion. At the rate of nearly a million a year, immigrants from southern and eastern Europe entered the United States through Ellis Island in search of prosperity. These mostly poor, uneducated, and unskilled immigrants settled in newly industrialized American cities (Oakes, 2005; Darling-Hammond, 2010). In 1909, Stanford University Education School dean Ellwood P. Cubberly described the problem as it was then conceptualized:

These southern and eastern Europeans are of a very different type from the north Europeans who preceded them. Illiterate, docile, lacking in self-reliance and initiave, and not possessing the Anglo-Teutonic conceptions of law, order, and government, their coming has served to dilute tremendously our national stock, and corrupt our civic life... Our city schools will soon be forced to give up the exceedingly democratic idea that all are equal and our society devoid of classes... and to begin a specialization of educational effort along many lines in an attempt to adapt the school to the needs of these many classes... Industrial and vocational training is especially significant of the changing conception of the school and the classes in the future expected to serve. (pp. 15-19)

The population boom created a tremendous increase in student enrollment.

Between 1880 and 1918, student enrollment rates increased by over 700\%, rising from about 200,000 to over 1.5 million students. Urban schools were dramatically impacted as large numbers of poor rural families joined European immigrants in pursuit of the 
promise of industrial affluence (Oakes, 2005). As a result, schools were no longer educating predominantly white Anglo-Saxon middle-class students. By $1909,58 \%$ of the students in 37 of the nation's largest cities were of foreign-born parentage (Cremin, 1964).

As the number of schools and students increased during the early 1900s, there was also increased social pressure for schools to do more. According to Oakes (2005):

Colleges and universities wanted a more standardized precollegiate education. Many of the middle class called for free public education available to all youth. Poor and immigrant families were eager for the economic benefits they believed schooling would provide their children. Businessmen were interested in acquiring a more productive and literate work force. Organized labor was concerned about who should control the training of workers. Progressive reformers sought humane solutions to the immense social problems confronting the burgeoning population of poor and immigrant youth. (p. 20)

Above all else, however, was a perceived need to exercise greater social control over a rapidly evolving citizenry (Oakes, 2005; Darling-Hammond, 2010).

An emerging belief suggested that public schools, if properly reformed, could achieve the economic and societal goals of all stakeholders. This call for education reform coincided with a time period formally referred to as the "Age of Efficiency" (Callahan, 1962). Inspired by Newtonian science, industrialists came to view the organization as a machine and were eager to embrace new methods of production in search of improved reliability and efficiency. Eventually, the assembly line would transform the conditions of industrial work. In factories, this equated to interchangeable, trained workers doing precisely designed repetitive tasks, orchestrated by a rhythm set by external bosses (Senge et al., 2102). Paving the way for these changes were the ideas of Frederick Winslow Taylor, the world's first modern efficiency expert (Rees, 2001). 
Around the turn of the $20^{\text {th }}$ century, Taylor introduced the idea of efficient production through the application of scientific management techniques in industrial settings. Taylor (1911) believed that industrial efficiency relied on truly scientific management that drew on clearly defined principles and natural laws. In order to increase output, Taylor sought the "right standards of performance and the standardization of the best methods of work" (Bobbitt, 1913).

As the principles of scientific management gained popularity in industry, businessmen and school administrators began applying Taylor's ideas to education (Oakes, 2005). In 1913, Franklin Bobbitt of the University of Chicago wrote:

At a time when so much discussion is being given to the possibilities of "scientific management" in the world of material production, it seems desirable that the principles of this more effective form of management be examined in order to ascertain the possibility of applying them to the problems of educational management and supervision. (p. 7)

Bobbitt (1913) went on to explain how this would be achieved:

As a foundation for all scientific direction and supervision of labor in the field of education, we need first to draw up in detail for each social or vocational class of students in our charge a list of all the abilities and aspects of personality for the training of which the school is responsible. Next we need to determine scales of measurement in terms of which these many different aspects of the personality can be measured. We must determine the amount of training that is socially desirable for each of these different abilities and state these amounts in terms of the scales of measurement. We must have progressive standards of attainment for each stage of advance in the normal development of each ability in question. When these four sets of things are at hand for each differentiated social or vocational class, then we shall have for the first time a scientific curriculum for education worthy of our present age of science. (p. 49)

Bobbitt's notion that each individual should be educated "according to his capabilities," led to a highly differentiated curriculum (Shepard, 2000). In other words, schools would offer something for everyone, but would not promise the same thing for 
everyone. By selecting students for various occupations and providing them with appropriate training and skills, schools fulfilled a necessary role within the industrial order (Oakes, 2005).

Bobbitt's vision to advance school reform by establishing different performance standards for different groups of students aligned with other Industrial Age assumptions applied to education. Social Darwinism, for example, provided "scientific" justification for schools to treat the children of various groups differently. By applying the theories of Charles Darwin to human society, social Darwinists saw certain groups of people as being of lesser social and moral development than others. They specifically argued that the survival or dominance of Anglo-Protestants in a competitive social environment proved that ethnic minorities and the poor were inherently inferior as a result of biologically determined developmental differences (Oakes, 2005). While conservative social Darwinists, including the well-known Herbert Spencer, held little hope that education could alter social conditions, more progressive social Darwinists adopted a contrary view, believing that education could play a vital role in directing the progress of mankind. According to Dewey (1897), "Education is the fundamental method of social progress and reform" and "the teacher is engaged, not simply in the training of individuals, but in the formation of the proper social life" (p. 80). Given the magnitude of individual differences among students attending schools, a system of curriculum differentiation aligned with the teachings of social Darwinism (Oakes, 2005).

A further outgrowth of Newtonian science and social theories that advanced a view of the world as predicable and static was that of behavioral psychology. Behavioral theories, including the work of B. F. Skinner, maintained that behaviors could be 
described scientifically without recourse to either internal physiological or hypothetical constructs, such as thoughts and beliefs (Baum, 1994). As a result of behavioral theories, human behavior came to be seen as both measurable and predictable. In regards to education reform, behavioral learning theories advanced the idea that intelligence is fixed and innate and, furthermore, differences in intelligence can be accurately measured. Based upon these measurements, individuals can be grouped together into manageable groups and prescribed the appropriate academic programming (Lambert et al., 2002). In this way, behaviorism also supported curriculum differentiation.

During the early 1900s, students were openly classified into various programs based upon their ethnic, racial, and economic background, a procedure considered scientific by social Darwinists and behaviorists and efficient by the standards of industrial production. Following World War I, however, the practice was called into question as more Americans consciously pursued an open and classless society. As a result, placement procedures used to separate children for instruction shifted from class-biased assignments to "ability" grouping based on the results of IQ tests. These tests were considered both objective and efficient measures of individual differences and, thus, represented a scientific means of separating students for instruction (Oakes, 2005).

Over time, even as the rigid tracking systems of the early $20^{\text {th }}$ century were dismantled in the United States, curriculum differentiation has remained a pervasive and salient feature of American schooling in the $21^{\text {st }}$ century (Oakes, 2005; DarlingHammond, 2010; Burris \& Garrity, 2008). In modern tracking systems, students are assigned to different levels of the same course, or to a course with a different curriculum that is either more or less rigorous (Burris \& Garrity, 2008; Lucas, 1999; Yonezawa, 
Wells, \& Serna, 2002). The rigor of the curriculum is also frequently associated with the effectiveness of instruction in the classroom (Darling-Hammond, 2010). Reserving the most rigorous curriculum and engaging instruction for select students is antithetical to the pursuit of achievement equity.

\section{The Unintended Consequences of Tracking Practices}

On the basis of assumptions about learning and schooling, education reform during the Industrial Age relied on curriculum differentiation to answer the calls of a wide variety of societal stakeholders, including middle class families, poor and immigrant families, businessmen, and progressive reformers. With the best of intentions, students were labeled, sorted, and provided with different kinds of instruction. Over time, like so many other school practices, tracking became so rooted in tradition that contemporary educators generally assume the practice is best for students. According to Oakes (2005), this belief is supported by a number of commonly held assumptions:

The first [assumption] is the notion that students learn better when they are grouped with other students who are considered to be like them academicallywith those who know the same things, who learn at the same rate, or who are expected to have similar futures. This assumption is usually expressed in two ways: first, that bright students' learning is likely to be held back if they are placed in mixed groups and, second, that the deficiencies of slow students are more easily remediated if they are placed in classes together. Another assumption is that slower students develop more positive attitudes about themselves and school when they are not placed in groups with others who are far more capable... A third assumption is that the placement processes used to separate students into groups both accurately and fairly reflect past achievement and native abilities... A fourth assumption is that it is easier for teachers to accommodate individual differences in homogeneous groups or that, in general, groups of similar students are easier to teach and manage. (pp. 6-7)

The problem is that these assumptions have not been confirmed through research.

In fact, in most cases, research has demonstrated the assumptions to be blatantly false. 
While the intentions of tracking policies and practices may have been in the best interests of students, it is clear that the effects are not (Oakes, 2005; 1992; Oakes, Gamoran, \& Page, 1992; Burris \& Garrity, 2008; Burris \& Welner, 2005; Welner \& Oakes, 1995; Wells \& Oakes, 1996; Wells \& Serna, 1996; Alvarez \& Mehan, 2006; Yonezawa \& Jones, 2006; Yonezawa, Wells, \& Serna, 2002).

As early as the 1970s, sociological and educational researchers had identified problems with tracking systems (Rosenbaum, 1999). In regards to the first assumptionthat students learn better when grouped with others like them academically-research has concluded that no group of students has been found to benefit consistently from being part of a homogeneous group. The results of hundreds of studies have left researchers fairly confident that bright students are not held back when in mixed-ability classrooms, and that the deficiencies of slower students are not more easily remediated when they are grouped together (Oakes, 2005). Contrary to the first assumption, many studies have found that homogeneous placements negatively impact the learning of average and slow students. Specifically, studies have found that students placed in low-track classes experience curriculum and instructional differences that dramatically restrict their knowledge and opportunities to learn. Oakes and Wells (1998) found that low-track classes provide students with fewer resources, a lower level curriculum, and a lesspowerful learning environment as compared to high-track classes. For example, lowtrack classes are more likely to be geared only to rote skills and test-oriented tasks, and teacher interaction in these classes is less motivating and less supportive (DarlingHammond, 2010; Eckstrom \& Villages, 1991; Garoman, 1989; Oakes, 2005). Another study confirmed that: 
Students segregated into low-track classes are often exposed to a limited range of cognitive tasks that do not stretch their higher order thinking and communicative skills, do not extend them to solve new and complex problems, and do not facilitate the transfer of knowledge gained in one situation to another situation. (Alvarez \& Mehan, 2006, p. 83)

Additional research demonstrates that students in low-track classes are rarely provided the opportunity to read actual books, conduct research and write, or to construct and solve problems (Cooper \& Sherk, 1989; Oakes, 2005). For the students of low-track classes, homogeneous grouping has significantly limited their learning opportunities and educational experiences.

The second assumption — that slower students feel better about themselves and school when they are in homogeneous groups - has also been proven false through research. A considerable amount of work has demonstrated that students placed in average and low-track classes do not develop positive attitudes (Oakes, 2005). Instead, placing students in low-track classes can lower students' sense of self-efficacy and selfesteem (George, 1993; Oakes, 2005). Wells and Serna (1996) found that being placed in low-track classes often has long-lasting negative consequences as students fall further and further behind their peers and become increasingly bored in school. When students' own perspectives of tracking were studied, it was discovered that students viewed tracking placements as unfair and generally desired more rigorous coursework (Yonezawa \& Jones, 2006).

Track placement has also been found to influence student behaviors (Oakes, 2005) and shape their peer groups (Hallinan \& Williams, 1990). Low-track students have been found to exhibit more school and classroom misconduct, participate in fewer extracurricular activities at school, be more alienated from school, and have higher drop- 
out rates (Shafer \& Olexa, 1971). Tracking also limits the opportunities that different kinds of students have to interact with one another and, thus, gain access to multiple perspectives (Darling-Hammond, 2010). Further exacerbating the negative effects of tracking are studies that suggest that it is difficult for students to move between tracks. In fact, it is more common for students to be moved to lower tracks than it is for students to be promoted to higher track classes (Braddock, 1990; Yonezawa, Wells, \& Serna, 2002). Moreover, it is widely documented that the negative consequences associated with being assigned to a low-track class disproportionately affect low-income and minority students.

Despite the assumption that student track placements are appropriate, accurate, and fair, research has demonstrated that grouping students in differentiated programs or courses often results in racially and socioeconomically segregated classrooms (Dornbusch, 1994; Oakes, 2005; Burris \& Welner, 2005; Oakes et al., 1992; Wells \& Serna, 1996; Yonezawa, Wells, \& Serna, 2002). Ethnicity has been found to affect track assignment with African American and Latino students frequently placed in the lowest level classes, even when they have equal or higher test scores or grades than their White and Asian peers, who are frequently placed in high-track or honors courses (Burris \& Welner, 2005; Oakes, 2005; Oakes et al., 1992; Wells \& Serna, 1996; Yonezawa, Wells, \& Serna, 2002). For example, Oakes' (2005) research demonstrated Latino students who scored near the $60^{\text {th }}$ percentile on standardized tests were less than half as likely as White or Asian students to be placed in college preparatory classes. Furthermore, even Latino students who scored above the $90^{\text {th }}$ percentile had only about a $50 \%$ chance of being placed in a college preparatory class, while their White and Asian counterparts were virtually assured such placements. Similar patterns were found for African American 
students as well (Darling-Hammond, 2010).

Socioeconomic status has also been found to affect track assignment with lowincome students frequently placed in the lowest level classes, even when they have equal or higher test scores or grades to mid-to-high-income students, who are frequently placed in high-track or honors courses (Burris \& Welner, 2005; Oakes, 2005; Oakes et al., 1992; Wells \& Serna, 1996; Yonezawa, Wells, \& Serna, 2002). According to Vanfossen, Jones, and Spade (1987), “a highly proficient student from a low socioeconomic background has only a 50-50 chance of being placed in a high track class" (quoted in Burris \& Welner, 2005, p. 595).

Even when policy permits student choice in the placement process, schools often maintain segregated classrooms. A 3-year, longitudinal case study of 10 schools found that providing students increased freedom when selecting classes was not a successful method for creating more heterogeneous high-track classes (Yonezawa, Wells, \& Serna, 2002). According to the researchers, school personnel managed to deny low- and highability students" petitions to change courses through "selective flexibility." For example, counselors and teachers blocked certain students from AP and honors classes by convincing the students that they had not taken the necessary pre-requisite courses needed to be successful in the higher-tracked classes. The researchers also found that students' own perceptions about their abilities limited track movement. Others were not willing to give up their peer group in order to move to higher-level courses (Yowenza, Wells, \& Serna, 2002). In other words, when offered the freedom to choose courses, the socially constructed views held by school personnel and students themselves about who belongs in which classes proved to be a barrier to establishing heterogeneous high-track classes. 
In other cases it was found that "elite" parents were influential in the continuance of tracking policies and practices. Specifically, the "local elites" relied on social and cultural capital to advance an agenda aimed at "maintaining a tracking structure, with separate and unequal educational opportunities for 'deserving' elite students and 'undeserving' non-elite students" (Wells \& Serna, 1996, p. 96). The researchers found that these parents were able to subtly influence school administrators when it came to tracking placements and policies (Wells \& Serna, 1996).

As indicated by the preceding review of research and literature, the effects of tracking have not matched the intentions of said policies and practices. Instead, the most challenging curricula and best instruction are reserved for a select group of students. Furthermore, with low-income and minority students overrepresented in low-track classes and underrepresented in high-track classes, tracking represents a major contributor to the continuing gaps in student achievement (Ascher, 1992; Garmoran, 1987; Gamoran \& Mare, 1989; Oakes, 2005; 1992). So, while educators may profess that it is more challenging to teach in heterogeneous classrooms, the evidence is clear that tracking policies and practices are no longer a viable educational solution in pursuit of achievement equity. In fact, emerging research on detracking American classrooms offer some promising results from this equality-minded approach to education in the $21^{\text {st }}$ century.

\section{The Success of Detracking}

Detracking generally entails an attempt to group students heterogeneously as a means of ensuring that all students, regardless of their race or class background or their academic ability, have access to high-quality curriculum, teachers, and material resources 
(Burris \& Welner, 2005; Rubin, 2006; Yonezawa \& Jones, 2006; Yonezawa et al., 2002).

Detracking initiatives are grounded in the established ideas that higher achievement

follows from a more rigorous curriculum and low-track classes, with unchallenging curricula, result in lower student achievement (Burris \& Welner, 2005). Advocates of detracking suggest that all normally functioning humans have the capacity to reason sufficiently well to finish high school and enter college when they are supported with the appropriate academic and social scaffolds (Bruner, 1986; Cicourel \& Mehan, 1985; Meier, 1995; Resnick, 1995). Thus, detracking calls upon educators to embrace a growth mindset. According to Dweck (2006):

The growth mindset is based on the belief that your basic qualities are things you can cultivate through your efforts. Although people may differ in every which way - in their initial talents and aptitudes, interests, and temperamentseveryone can change and grow through application and experience. (p. 7)

This is a notable deviation from the early $20^{\text {th }}$ century assumption that intelligence is innate and unchanging and that different groups of students should be given different types of curriculum based upon measures of their intelligence.

Detracking was successful at the Preuss School on the University of California, San Diego campus. The Preuss School enrolls only students from low-income families and is dedicated to preparing all of them for college. The school provides a wide range of social and academic supports but enrolls students in only one college-preparatory track. Among the first graduating class at the Preuss School, $80 \%$ of the students went on to attend a 4-year college, while the remaining $20 \%$ attended community colleges with their transfer to University of California schools guaranteed in 2 years (Alvarez \& Mehan, 2006). 
In New York, the Rockville Centre School District experienced encouraging results following its multiyear detracking initiative. In Rockville Centre, the initiative grew out of a goal to increase the number of high school graduates earning New York State Regents diplomas. Although the district was already earning Regents diplomas at a rate $20 \%$ higher than the state average, the district's African American, Latino, lowincome, and special education students were earning Regents diplomas in disproportionately low numbers. After only one year of heterogeneous grouping, the passing rate for African American and Latino students increased from $48 \%$ to $77 \%$, while the passing rate for White and Asian American students increased from 85\% to 94\% (Burris \& Welner, 2005). Between 1996 and 2008, the Regents diploma rate for minority students rose from $32 \%$ to $94 \%$. Furthermore, $87 \%$ of special education students in Rockville Centre were also earning Regents diplomas by 2008. As a result of detracking, the gap nearly disappeared between Rockville Centre students who earned the New York State Regents diploma, and the percentage of African American, Latino, and special education students earning Regents diplomas at Rockville Centre far outpaced the percentage of White students in New York earning Regents diplomas (Burris \& Garrity, 2009).

At Railside School in California not only did a detracked approach lead to increased academic achievement, but it also promoted respect and responsibility among students. Boaler (2006) uses the term "relational equity" to describe the transformation that took place at Railside School as students developed respectful relationships with one another through a collaborative problem-solving approach in which students worked together and learned to appreciate the different insights, methods, and perspectives that different students offered in the collective solving of problems. 
If nothing else, the aforementioned examples provide a glimpse of what the American education system can be in the absence of century-old tracking policies and practices. Other nations have experienced success as a result of more equitable schooling practices. Finland, for example, propelled achievement to the top of the international rankings and closed what was once a large, intractable achievement gap after dismantling a rigid tracking system that allocated differential access to knowledge to the nation's students (Darling-Hammond, 2010). The Finnish success story demonstrates a need for an educational system to develop the talents of all students to high levels in order to meet the demands of a knowledge-based economy.

\section{Summary}

In an era in which educators aspire for all students to perform at high levels, achievement equity is not a reality for all children. Consequently, the "achievement gap" that is so widely debated in the field remains a significant challenge in $21^{\text {st }}$ century education. As low-income and minority, specifically African American and Latino, students continue to underperform academically as compared to their peers, some reformers have suggested that gaps in achievement are correlated to gaps in educational opportunities. After all, low-income and minority students are overrepresented in lowtrack classes and underrepresented in high-track classes (Ascher, 1992; Garmoran, 1987; Gamoran \& Mare, 1989; Oakes, 2005; 1992). Indeed, the research and literature suggest that tracking policies and practices do not align with the goals of standards-based education reform and will not satisfy the demands of a knowledge-based society (Darling-Hammond, 2010; Oakes, 2005; Boykin \& Noguera, 2009). Accordingly, this study examined the relationship between tracking policies and practices and the 
educational outcomes of students. The forthcoming chapter explains the methodology employed to complete the study. 


\section{CHAPTER III}

\section{METHODOLOGY}

This chapter describes the methods used in conducting the research study. The research design and procedures are discussed. The population and sample are identified. Detailed information regarding instrumentation, including efforts to establish validity and reliability, is provided. This chapter concludes by presenting information about the steps involved in data analysis and interpretation.

The study used secondary data from the Illinois State Board of Education. To address the problem that not all students are achieving at high levels, this study assessed the differences between students who have completed AP/Honors courses and those who have not. Findings may contribute to the closing of achievement gaps identified by socioeconomic status and race, and potentially lead to increased high school graduation and college enrollment rates. Accordingly, the results of this study are of practical significance to researchers and practitioners interested in achieving equality of opportunities in public education.

\section{Research Design}

To address the research questions of this study, a cross-sectional research design using secondary data from the Illinois State Board of Education was utilized. The purpose of this study was to examine the relationship and differences between students who have completed AP/Honors courses and those who have not in Illinois public high 
schools. Studying the relationship between ACT scores and high-track course completion among students across the state of Illinois allows inferences to be made regarding academic performance and track placement in schools across the nation. According to Creswell (2009), "A survey design provides a quantitative or numeric description of trends... of a population by studying a sample of that population" (p. 145). A survey design was the preferred type of data collection procedure for this study due to the economy of the design (Creswell, 2009). By identifying attributes of a large population from a sample, the research design provided a means of assessing the relationship between tracking policies and practices and educational outcomes. By examining students' participation in AP/Honors courses in relation to their ACT scores, the survey was cross-sectional. Data collection consisted of a structured record review of secondary data from the Illinois State Board of Education.

\section{The Population and Sample}

Using secondary data from the Illinois State Board of Education, this study examined the course placement and standardized test score performance of Illinois public high school students. The data set included information on 145,560 Illinois high school students who completed the ACT during the 2012-2013 school year. Students' socioeconomic status and race were also considered in analyzing the data. Among students included in the data set 80,939 (56\%) were identified as White; 29,437 (20\%) were identified as Latino; 24,953 (17\%) were Black; 6,302 (4\%) were identified as Asian; 3,426 (2\%) were identified as Two or More Races; 377 (less than 1\%) were identified as American Indian; and 123 (less than 1\%) were identified as Native Hawaiian or other Pacific Island. Among all students included in the sample 87,223 (60\%) did not 
participate in the National School Lunch Program and 58,337 (40\%) participated in the National School Lunch Program.

\section{Instrumentation}

The ACT college readiness assessment is a curriculum- and standards-based educational and career planning tool that assesses students' academic readiness for college. The ACT is administered in all 50 states and accepted by all 4-year colleges and universities in the United States. This assessment, which is taken by more than 1.6 million high school students every year, consists of four multiple-choice tests: English, mathematics, reading, and science (ACT, 2013).

The English test is a 75-question, 45-minute assessment that measures standard written English and rhetorical skills. In regards to usage and mechanics, the English test covers punctuation, grammar and usage, and sentence structure. In regards to rhetorical skills, the English test covers strategy, organization, and style. The English test is comprised of five prose passages, each followed by multiple-choice questions. Different passage types are used throughout the test to provide variety (ACT, 2013).

The mathematics test is comprised of 60 questions and is to be completed in 60 minutes. Content for the mathematics test is based on six content areas: pre-algebra, elementary algebra, intermediate algebra, coordinate geometry, plane geometry, and trigonometry. The test requires reasoning skills to solve practical problems in mathematics and requires students to possess knowledge of basic formulas and computational skills. Students may use an approved calculator to complete the mathematics test (ACT, 2013). 
The reading test is a 40 -question, 35-minute assessment that measures reading comprehension. The test comprises four sections, each containing one long or two shorter prose passages that are representative of the level and type of reading required in firstyear college courses. Passages on topics in social studies, natural sciences, prose fiction, and the humanities are included. Each passage is accompanied by a set of multiplechoice test questions. In sections that contain two short passages, some of the questions involve both of the passages in the section. These questions do not test the rote recall of facts from outside the passage, isolated vocabulary items, or rules of formal logic. Instead, the test focuses on the complementary and supportive skills that readers must use in studying written materials across a range of subject areas. Specifically, students are required to use referring and reasoning skills to determine main ideas; locate and interpret significant details; understand sequences of events; make comparisons; comprehend cause-effect relationships; determine the meaning of context-dependent words, phrases, and statements; draw generalizations; and analyze the author's or narrator's voice and method (ACT, 2013).

The science test, comprised of 40 questions to be completed in 35 minutes, measures the interpretation, analysis, evaluation, reasoning, and problem-solving skills required in the natural sciences. The test presents several sets of scientific information, each followed by a number of multiple-choice test questions. The scientific information is presented as data (i.e., graphs, tables, and other schematic forms), research summaries (i.e., descriptions of one or more related experiments), and conflicting viewpoints (i.e., expressions of several related hypotheses or views that are inconsistent with one another). Students are expected to recognize and understand basic features of, and concepts related 
to, the provided information; examine critically the relationship between the information provided and the conclusions drawn or hypotheses developed; and generalize from given information and draw conclusions, gain new information, or make predictions (ACT, 2013).

ACT college readiness assessment scores are computed based upon the number of questions on each test that the student answers correctly. Points are not deducted for incorrect answers; thus, there is no penalty for guessing. Raw scores (i.e., the number of correct responses on each test) are then converted to scale scores, which have the same meaning for all the different forms of the ACT, no matter which test date a test was taken. A student's Composite Score and each test score (English, mathematics, Reading, and science) range from a low score of 1 to a high score of 36 . The Composite Score is the average of a student's four test scores, rounded to the nearest whole number. Fractions less than one-half are rounded down, whereas, fractions one-half or more are founded up. The ACT college readiness benchmark scores are as follows: English $=18$, mathematics $=22$, reading $=21$, and science $=24($ ACT, 2013 $)$.

\section{Variables in the Study}

The purpose of this study was to examine the relationship and differences between students who have completed AP/Honors courses and those who have not in Illinois public high schools. The independent variables were socioeconomic status, race, and AP/Honors placement. For the purposes of this study, socioeconomic status was defined by participation in the National School Lunch Program, a federally assisted program that provides qualifying students with free or reduced meals in over 100,000 American schools. Race was defined through three groups: Black students, Latino 
students, and White students. Advanced Placement, or AP, courses are high-track courses created by the College Board to offer college-level curriculum and examinations to high school students. Courses receiving the AP designation are audited by the College Board to ascertain that the content satisfies the AP curriculum. Honors courses are defined as high-track, or college-preparatory, courses that do not receive a formal designation from the College Board but still offer a more rigorous curriculum than alternative courses within the school or district. For the purposes of this study, AP/Honors placement represented students' participation in high-track courses in the following content areas: English, mathematics, science, and social studies/reading.

The dependent variable was standardized test scores as reported by ACT in the following content areas: English, mathematics, science, and reading. All variables studied were reported to the Illinois State Board of Education by individual schools and districts across the state.

\section{Data Analysis and Interpretation}

The statistical technique known as analysis of variance (ANOVA) was used to examine the relationship and differences between students who have completed AP/Honors courses and those who have not in Illinois public high schools. ANOVA is a hypothesis-testing procedure used to evaluate mean differences between two or more treatments. The goal of ANOVA is to determine whether a treatment effect exists. Treatment effects are said to cause variance when the differences between treatments are significantly greater than can be explained by chance alone. In ANOVA, variance is used to measure how big the differences should be if there is no treatment effect. The major advantage of ANOVA over $t$ tests is the ability to compare two or more factors, such as 
socioeconomic status, race, and AP/Honors placement (Gravetter \& Wallnau, 2007).

In the case of the second research question, where there are three treatments, post hoc tests were conducted following the ANOVA to determine exactly which mean differences are statistically significant and which are not. Specifically, Tukey's HSD test was conducted to compare the individual treatments two at a time. This comparison is possible through the calculation of the honestly significant difference (HSD), which represents the single value that determines the minimum significance between treatment means that is necessary for significance (Gravetter \& Wallnau, 2007).

\section{Internal and External Validity}

The research design utilized for this study suggests that an independent variable leads to the dependent variable. In other words, students exposed to AP/Honors courses perform better on the ACT because they were afforded better educational experiences and vice versa. Threats to internal validity, however, may raise questions about the researcher's ability to conclude that the interaction affected an outcome and not some other factor. Internal validity threats are procedures, factors, or experiences of the participants that threaten the researcher's ability to draw correct inferences from the data (Creswell, 2009). Accordingly, actions were taken to mitigate any threats to internal validity. For example, to address threats of regression and selection, the researcher utilized a sample including all White, Black, and Latino public high school students within the state of Illinois.

External validity threats arise when researchers draw incorrect inferences from the sample data to other persons, other settings, or past or future situations (Creswell, 2009). In generalizing this particular study, findings from Illinois' high schools were used to 
make inferences about other similar settings across the nation. Again, action was taken on the part of the researcher to minimize threats to external validity. For example, the researcher studied all White, Black, and Latino Illinois' public high school students to address the threat of interaction of selection and treatment.

\section{Summary}

Recognizing that achievement equity is not currently a reality for all students, this study assessed the differences between students who have completed AP/Honors courses and those who have not. Using a cross-sectional survey design, the study examined secondary data from the Illinois State Board of Education indicating high school students' socioeconomic status, race, placement in AP/Honors courses, and ACT scores. The statistical technique called analysis of variance was used in combination with post hoc tests to examine the relationship and differences between students who have completed AP/Honors courses and those who have not in Illinois public high schools. Thus, findings may contribute to the closing of achievement gaps identified by socioeconomic status and race, and potentially lead to increased high school graduation and college enrollment rates. 


\section{CHAPTER IV}

\section{ANALYSIS OF THE DATA}

This chapter provides an analysis of the data in relation to the research questions.

To examine the relationship and differences between students who have completed

Advanced Placement (AP)/Honors courses and those who have not in traditional Illinois

public high schools, the following research questions were explored:

1. What are the differences in ACT scores between students who have completed at least one AP/Honors (English, mathematics, science, and/or social studies) course and those who have not?

2. What are the differences in ACT scores between (a) Black students and White students who have completed at least one AP/Honors (English, mathematics, science, and/or social studies) course when income is accounted for, (b) Latino students and White students who have completed at least one AP/Honors (English, mathematics, science, and/or social studies) course when income is accounted for, and (c) Black and Latino students who have completed at least one AP/Honors (English, mathematics, science, and/or social studies) course when income is accounted for?

3. What are the differences in ACT scores between (a) Black students who have completed at least one AP/Honors (English, mathematics, science, and/or social studies) course and those who have not, (b) Latino students who have completed at least one AP/Honors (English, mathematics, science, and/or social studies) course and those who have not, and (c) White students who have completed at least one AP/Honors (English, mathematics, science, and/or social studies) course and those who have not?

4. What are the differences in ACT scores between low-income students and non low-income students who have completed at least one AP/Honors (English, mathematics, science, and/or social studies) course?

5. What are the differences in ACT scores between (a) low-income students who have completed at least one AP/Honors (English, mathematics, science, and/or social studies) course and those who have not, and (b) non low-income students who have completed at least one AP/Honors (English, mathematics, science, and/or social studies) course and those who have not? 


\section{Descriptive Statistics}

To answer the research questions, the study examined secondary data from the Illinois State Board of Education (ISBE). Data were collected for a total of 145,560 Illinois public high school students, who completed the ACT during the 2012-2013 school year. The independent variables for the study included socioeconomic status, race, and $\mathrm{AP} /$ Honors course placement.

For the purposes of the study, socioeconomic status was defined by participation or non-participation in the National School Lunch Program. The National School Lunch Program is a federally assisted meal program that provides nutritionally balanced, lowcost or free lunches to qualifying children each school day. In the state of Illinois, the percentage of students considered low-income within individual schools and districts is generally determined based upon student participation in the National School Lunch Program. For that reason, students participating in the National School Lunch Program were identified as "low-income" students, whereas, students not participating in the program were considered "non low-income" students. Of the 145,560 students studied, 87,223 students did not participate in the National School Lunch Program and 58,337 students participated in the National School Lunch Program. Accordingly, 59.9\% of the students studied were considered non low-income and $40.1 \%$ of the students studied were considered low-income.

Another independent variable examined, race, is reported to the ISBE by individual school districts based upon the information collected from students and their families. As reported to the ISBE, students are identified as "American Indian or Alaska Native," "Asian," "Black or African American," "Hispanic or Latino," "Native Hawaiian 
or Other Pacific Islander," "Two or More Races," or "White." To address the first three research questions, students identifying as "Black or African American," "Hispanic or Latino," or "White," were considered in the study. Of these students, 80,939 children, or $55.6 \%$ of the total population, are identified as White. Latino students made up $20.2 \%$ of the total population with 29,437 students, and the 24,953 Black students represented $17.1 \%$ of the total population.

The final independent variable considered for this study was AP/Honors course placement. Advanced Placement, or AP, courses are accelerated courses created by the College Board to offer college-level curriculum and examinations to high school students. These courses are audited by and receive the AP designation from the College Board. For the purposes of this study, Honors courses are defined as accelerated, or college-preparatory, courses that do not receive a formal designation from the College Board but are intended to offer a more rigorous curriculum than alternative courses within the school or district. Data were collected on students enrolled in AP/Honors courses in the subject areas of English, mathematics, science, and social studies. Participation in AP/Honors courses constituted students' exposure to high-track courses in these subject areas. In English, 24,551 students (16.9\%) were enrolled in AP/Honors courses, whereas, 121,009 (83.1\%) did not participate in English high-track classes. In mathematics, 22,243 students (15.3\%) were enrolled in AP were enrolled in AP/Honors courses, whereas, 123,317 (84.7\%) did not participate in mathematics high-track classes. In science, 20,686 students (14.2\%) were enrolled in AP/Honors courses, whereas, 124,874 (85.8 percent) did not participate in science high-track classes. In comparison to other high-track course offerings, the greatest number of students participated in 
AP/Honors social studies courses. A total of 37,329 students $(25.6 \%)$ enrolled in these courses, while 108,231 (74.4\%) did not participate in social studies high-track courses.

The instrument used to measure student performance was the ACT, a college readiness assessment administered to all students included in the study whether or not they completed AP/Honors courses. The ACT consists of four multiple-choice tests: English, mathematics, science, and reading (ACT, 2013). In analyzing the data, English ACT scores were used to examine the relationship and differences between students who completed AP/Honors English courses and those who did not. Similarly, mathematics ACT scores were used to examine the relationship and differences between students who completed AP/Honors mathematics courses and those who did not. Science ACT scores were used to examine the relationship and differences between students who completed AP/Honors science courses and those who did not. Finally, reading ACT scores were used to examine the relationship and differences between students who completed AP/Honors social studies courses and those who did not. This final pairing is based upon the notions that the content on the reading ACT assessment is often specific to social studies and participation in AP/Honors social studies courses generally involves extensive reading.

ACT test scores (English, mathematics, science, and reading) range from a low score of 1 to a high score of 36 . The ACT college readiness benchmark score for English is 18 , in mathematics it is 22 , in science it is 24 , and in reading a score of at least 21 is desired (ACT, 2013). Of the 144,441 Illinois students who completed the English ACT assessment during the 2012-2013 school year, a mean score of 19.74 was calculated. Among 144,564 Illinois students who completed the mathematics ACT assessment, the 
mean score was calculated to be 20.49. A mean score of 20.27 was calculated for the 144,484 Illinois students who completed the science ACT assessment. And of the 144,496 Illinois students who completed the reading ACT assessment, a mean score of 19.57 was calculated.

\section{Research Question 1}

The first research question examined the differences in ACT scores between students who have completed at least one AP/Honors (English, mathematics, science, and/or social studies) course and those who have not. Therefore, this research question examines two treatment groups: (a) students who completed at least one AP/Honors course, and (b) students who completed only lower track courses. Students in both groups completed the ACT and results indicated variability between treatment means in all four of the content areas studied (English, mathematics, science, and social studies/reading). The means and standard deviations are presented in Table 13.

For the purposes of this research question, the statistical technique known as analysis of variance (ANOVA) was used to measure the amount of variability and explain where it comes from. Data were screened to ensure that assumptions of factorial ANOVA were fulfilled. A univariate ANOVA was conducted for each content area studied. Specifically, the ACT English assessment results of students enrolled in at least one AP/Honors English course were compared to the ACT English assessment results of students who only completed lower track English courses; the ACT mathematics assessment results of students enrolled in at least one AP/Honors mathematics course were compared to the ACT mathematics assessment results of students who only completed lower track mathematics courses; the ACT science assessment results of 
students enrolled in at least one AP/Honors science course were compared to the ACT science assessment results of students who only completed lower track science courses; and the ACT reading assessment results of students enrolled in at least one AP/Honors social studies course were compared to the ACT reading assessment results of students who only completed lower track social studies courses. The summary results of ANOVA are presented in Table 14.

Table 13

Differences in Students' ACT Mean Scores by Content Area

\begin{tabular}{|c|c|c|c|}
\hline & $\mathrm{N}$ & $M$ & $S D$ \\
\hline \multicolumn{4}{|l|}{ English } \\
\hline Participated in AP/Honors English course(s) & 24,500 & 25.89 & 5.87 \\
\hline Participated in lower track English course(s) & 119,941 & 18.49 & 6.11 \\
\hline \multicolumn{4}{|l|}{ Mathematics } \\
\hline Participated in AP/Honors mathematics course(s) & 22,204 & 28.08 & 4.75 \\
\hline Participated in lower track mathematics course(s) & 122,360 & 19.12 & 4.36 \\
\hline \multicolumn{4}{|l|}{ Science } \\
\hline Participated in AP/Honors science course(s) & 20,657 & 25.82 & 4.91 \\
\hline Participated in lower track science course(s) & 123,827 & 19.35 & 4.97 \\
\hline \multicolumn{4}{|l|}{ Reading } \\
\hline Participated in AP/Honors social studies course(s) & 37,255 & 24.13 & 5.98 \\
\hline Participated in lower track social studies course(s) & 107,241 & 17.98 & 5.51 \\
\hline
\end{tabular}

Table 14

ANOVA Summary Table

\begin{tabular}{lcccc}
\hline & $\mathrm{F}\left(\mathrm{df}_{\mathrm{b}}, \mathrm{df}_{\mathrm{w}}\right)^{\mathrm{a}}$ & $\mathrm{F}$ & $\mathrm{p}$ & $\mathrm{ES}$ \\
\hline English & $(1,144,439)$ & $30,317.65$ & $<.001^{\mathrm{b}}$ & 0.173 \\
Mathematics & $(1,144,562)$ & $77,070.52$ & $<.001$ & 0.348 \\
Science & $(1,144,482)$ & $30,156.02$ & $<.001$ & 0.173 \\
Social Studies/Reading & $(1,144,494)$ & $32,975.08$ & $<.001$ & 0.186 \\
\hline
\end{tabular}

${ }^{\mathrm{a}} \mathrm{df}_{\mathrm{b}}$ - degrees of freedom between groups, $\mathrm{df}_{\mathrm{w}}-$ degrees of freedom within groups

${ }^{\mathrm{b}}$ Significant at 0.01 level of significance 
As displayed in Table 13, students who completed at least one AP/Honors English course earned a mean score of 25.89 (S.D. $=5.87)$ on the English ACT assessment, whereas, students who completed only lower track English courses earned a mean score of 18.49 (S.D. $=6.11$ ) on the English ACT assessment. As shown in Table 14, the ANOVA revealed a statistically significant difference in English ACT performance between students who completed at least one AP/Honors English course and those who did not, $F(1,144,439)=30,317.65, p<.001, \eta^{2}=0.173$. An effect size of 0.173 indicates that $17.3 \%$ of the amount of variance between English ACT scores can be attributed to participation in at least one AP/Honors English course. An effect size between $10 \%$ and $25 \%$ suggests a medium strength treatment effect. Anything below $10 \%$ is considered to have a small effect, and anything above 25\% suggests a large effect (Cohen, 1988).

Students who completed at least one AP/Honors mathematics course earned a mean score of 28.08 (S.D. $=4.75)$ on the mathematics ACT assessment, while students who completed only lower track mathematics courses earned a mean score of 19.12 (S.D. $=4.36$ ) on the same assessment. The ANOVA revealed a statistically significant difference in mathematics ACT performance between students who completed at least one AP/Honors mathematics course and those who did not, $F(1,144,562)=77,070.52, p$ $<.001, \eta^{2}=0.348$. The effect size revealed a large treatment effect with approximately $35 \%$ of the variance in mathematics ACT scores attributable to participation in at least one $\mathrm{AP} /$ Honors mathematics course.

On the science ACT assessment, students who completed at least one AP/Honors science course earned a mean score of $25.82($ S.D. $=4.96)$, whereas, students who completed only lower track science courses earned a mean score of 19.35 (S.D. $=4.91)$. 
The ANOVA revealed a statistically significant difference in mathematics ACT performance between students who completed at least one AP/Honors science course and those who did not, $F(1,144,482)=30,156.02, p<.001, \eta^{2}=0.173$. The effect size revealed a medium treatment effect with approximately $17 \%$ of the variance in science ACT scores attributable to participation in at least one AP/Honors science course.

Students who completed at least one AP/Honors social studies course earned a mean score of 24.13 (S.D. $=5.98)$ on the reading ACT assessment, while students who completed only lower track social studies courses earned a mean score of 17.98 (S.D. $=$ 5.51) on the reading ACT assessment. The ANOVA revealed a statistically significant difference in reading ACT performance between students who completed at least one AP/Honors social studies course and those who did not, $F(1,144,494)=32,975.08, p<$ $.001, \eta^{2}=0.186$. The effect size revealed a medium treatment effect with approximately $19 \%$ of the variance in reading ACT scores attributable to participation in at least one AP/Honors social studies course.

\section{Research Question 2}

The second research question examined the differences in ACT scores between (a) Black students and White students who have completed at least one AP/Honors (English, mathematics, science, and/or social studies) course when income is accounted for, (b) Latino students and White students who have completed at least one AP/Honors (English, mathematics, science, and/or social studies) course when income is accounted for, and (c) Black and Latino students who have completed at least one AP/Honors (English, mathematics, science, and/or social studies) course when income is accounted for. To account for income, data were filtered to compare students participating in the 
National School Lunch Program to one another and students who were not eligible to participate in the National School Lunch Program to one another. In other words, lowincome students were compared to other low-income students and non low-income students were compared to other non low-income students. For the purposes of the research question, data were also filtered to examine students in three racial groups: White, Black or African American, and Latino or Hispanic. A univariate ANOVA was completed for each content area studied, and Tukey's HSD post hoc tests were conducted to determine mean differences for every possible paired combination of race groups. Among non low-income students, ACT mean scores varied across all four content areas studied (English, mathematics, science, and social studies/reading) depending on students' race. The means and standard deviations are presented in Table 15 .

Table 15

Differences in Non Low-Income ACT Mean Scores by Race

\begin{tabular}{lrrr}
\hline & $\mathrm{N}$ & $M$ & $S D$ \\
\hline English & & & \\
White & 12,373 & 28.23 & 4.52 \\
Black or African American & 885 & 23.66 & 5.27 \\
Latino & 1,404 & 25.34 & 5.32 \\
Mathematics & & & \\
White & 13,388 & 29.18 & 3.97 \\
Black or African American & 528 & 24.59 & 4.74 \\
Latino & 1,173 & 26.58 & 4.60 \\
Science & & & \\
White & 11,447 & 27.16 & 4.31 \\
Black or African American & 550 & 22.98 & 4.32 \\
Latino & 1,194 & 24.30 & 4.64 \\
Reading & & & \\
White & 20,378 & 25.79 & 5.49 \\
Black or African American & 1,304 & 21.32 & 5.43 \\
Latino & 2,420 & 22.92 & 5.76 \\
\hline
\end{tabular}


Similarly, among low-income students, ACT mean scores varied across all four content areas studied (English, mathematics, science, and social studies/reading) depending on students' race. The means and standard deviations are presented in Table 16.

Table 16

Differences in Low-Income ACT Mean Scores by Race

\begin{tabular}{lrrr}
\hline & $\mathrm{N}$ & $M$ & $S D$ \\
\hline English & & & \\
White & 1,412 & 25.30 & 5.16 \\
Black or African American & 2,111 & 19.34 & 5.08 \\
Latino & 3,269 & 20.46 & 5.08 \\
Mathematics & & & \\
White & 1,019 & 26.81 & 4.31 \\
Black or African American & 840 & 20.74 & 4.40 \\
Latino & 1,713 & 23.12 & 4.35 \\
Science & & & \\
White & 1,056 & 24.91 & 4.48 \\
Black or African American & 977 & 20.00 & 4.09 \\
Latino & 1,990 & 21.33 & 4.13 \\
Reading & & & \\
White & 2,162 & 23.51 & 5.61 \\
Black or African American & 2,390 & 18.91 & 5.01 \\
Latino & 3,966 & 19.78 & 5.00 \\
\hline
\end{tabular}

To address the first component of the research question, the ACT performance of White students who completed at least one AP/Honors course was compared to the ACT performance of Black students who completed at least one AP/Honors course. Among non low-income students, White children who completed at least one AP/Honors English course earned a mean score of 28.23 (S.D. $=4.52)$ on the English ACT assessment, while Black children who completed at least one AP/Honors English course earned a mean score of 23.66 (S.D. = 5.27) on the English ACT assessment. Tukey's post hoc test 
determined the mean difference in English ACT performance between non low-income White and Black students who completed at least one AP/Honors English course (4.57) to be statistically significant at the 0.01 level of significance. In regards to mathematics, White children who completed at least one AP/Honors mathematics course earned a mean score of 29.18 (S.D. $=3.97)$ on the mathematics ACT assessment, while Black children who completed at least one AP/Honors mathematics course earned a mean score of 24.59 (S.D. $=4.74$ ) on the mathematics ACT assessment. Tukey's post hoc test determined the mean difference in mathematics ACT performance between non lowincome White and Black students who completed at least one AP/Honors mathematics course (4.58) to be statistically significant at the 0.01 level of significance. In science, White children who completed at least one AP/Honors science course earned a mean score of $27.16($ S.D. $=4.31)$ on the science ACT assessment, while Black children who completed at least one AP/Honors science course earned a mean score of 22.98 (S.D. $=$ 4.32) on the same assessment. Tukey's post hoc test determined the mean difference in science ACT performance between non low-income White and Black students who completed at least one AP/Honors science course (4.18) to be statistically significant at the 0.01 level of significance. In regards to social studies/reading, White children who completed at least one AP/Honors social studies course earned a mean score of 25.79 $(\mathrm{S} . \mathrm{D} .=5.49)$ on the reading ACT assessment, while Black children who completed at least one AP/Honors social studies course earned a mean score of $21.32($ S.D. $=5.43)$ on the reading ACT assessment. Tukey's post hoc test determined the mean difference in reading ACT performance between non low-income White and Black students who completed at least one AP/Honors social studies course (4.47) to be statistically 
significant at the 0.01 level of significance.

Among low-income students, White children who completed at least one AP/Honors English course earned a mean score of 25.30 (S.D. = 5.16) on the English ACT assessment, while Black children who completed at least one AP/Honors English course earned a mean score of $19.34($ S.D. $=5.08)$ on the English ACT assessment. Tukey's post hoc test determined the mean difference in English ACT performance between low-income White and Black students who completed at least one AP/Honors English course (5.96) to be statistically significant at the 0.01 level of significance. In regards to mathematics, White children who completed at least one $\mathrm{AP} /$ Honors mathematics course earned a mean score of $26.81($ S.D. $=4.31)$ on the mathematics ACT assessment, while Black children who completed at least one AP/Honors mathematics course earned a mean score of $20.74($ S.D. $=4.40)$ on the mathematics ACT assessment. Tukey's post hoc test determined the mean difference in mathematics ACT performance between low-income White and Black students who completed at least one AP/Honors mathematics course (6.07) to be statistically significant at the 0.01 level of significance. In science, White children who completed at least one $\mathrm{AP} /$ Honors science course earned a mean score of 24.91 (S.D. $=4.48)$ on the science ACT assessment, while Black children who completed at least one $\mathrm{AP} /$ Honors science course earned a mean score of 20.00 $($ S.D. $=4.09)$ on the same assessment. Tukey's post hoc test determined the mean difference in science ACT performance between low-income White and Black students who completed at least one $\mathrm{AP} /$ Honors science course (4.90) to be statistically significant at the 0.01 level of significance. In regards to social studies/reading, White children who completed at least one AP/Honors social studies course earned a mean score of 23.51 
$(\mathrm{S} . \mathrm{D} .=5.61)$ on the reading ACT assessment, while Black children who completed at least one AP/Honors social studies course earned a mean score of 18.91 (S.D. $=5.01$ ) on the reading ACT assessment. Tukey's post hoc test determined the mean difference in reading ACT performance between low-income White and Black students who completed at least one AP/Honors social studies course (4.60) to be statistically significant at the 0.01 level of significance.

To satisfy the second component of the research question, the ACT performance of White students who completed at least one AP/Honors course was compared to the ACT performance of Latino students who completed at least one AP/Honors course. Among non low-income students, White children who completed at least one AP/Honors English course earned a mean score of 28.23 (S.D. = 4.52) on the English ACT assessment, while Latino children who completed at least one AP/Honors English course earned a mean score of $25.34($ S.D. $=5.32)$ on the English ACT assessment. Tukey's post hoc test determined the mean difference in English ACT performance between non low-income White and Latino students who completed at least one AP/Honors English course (2.89) to be statistically significant at the 0.01 level of significance. In regards to mathematics, White children who completed at least one AP/Honors mathematics course earned a mean score of $29.18($ S.D. $=3.97)$ on the mathematics ACT assessment, while Latino children who completed at least one AP/Honors mathematics course earned a mean score of 26.58 (S.D. $=4.60)$ on the mathematics ACT assessment. Tukey's post hoc test determined the mean difference in mathematics ACT performance between non low-income White and Latino students who completed at least one AP/Honors mathematics course (2.60) to be statistically significant at the 0.01 level of significance. 
In science, White children who completed at least one AP/Honors science course earned a mean score of 27.16 (S.D. $=4.31)$ on the science ACT assessment, while Latino children who completed at least one AP/Honors science course earned a mean score of $24.30($ S.D. $=4.64)$ on the same assessment. Tukey's post hoc test determined the mean difference in science ACT performance between non low-income White and Latino students who completed at least one AP/Honors science course (2.86) to be statistically significant at the 0.01 level of significance. In regards to social studies/reading, White children who completed at least one AP/Honors social studies course earned a mean score of 25.79 (S.D. $=5.49)$ on the reading ACT assessment, while Latino children who completed at least one AP/Honors social studies course earned a mean score of 22.92 (S.D. $=5.76)$ on the reading ACT assessment. Tukey's post hoc test determined the mean difference in reading ACT performance between non low-income White and Latino students who completed at least one AP/Honors social studies course (2.87) to be statistically significant at the 0.01 level of significance.

Among low-income students, White children who completed at least one AP/Honors English course earned a mean score of 25.30 (S.D. = 5.16) on the English ACT assessment, while Latino children who completed at least one AP/Honors English course earned a mean score of $20.46($ S.D. $=5.08)$ on the English ACT assessment. Tukey's post hoc test determined the mean difference in English ACT performance between low-income White and Latino students who completed at least one AP/Honors English course (4.84) to be statistically significant at the 0.01 level of significance. In regards to mathematics, White children who completed at least one AP/Honors mathematics course earned a mean score of $26.81($ S.D. $=4.31)$ on the mathematics ACT 
assessment, while Latino children who completed at least one AP/Honors mathematics course earned a mean score of $23.12($ S.D. $=4.35)$ on the mathematics ACT assessment. Tukey's post hoc test determined the mean difference in mathematics ACT performance between low-income White and Latino students who completed at least one AP/Honors mathematics course (3.69) to be statistically significant at the 0.01 level of significance. In science, White children who completed at least one AP/Honors science course earned a mean score of 24.91 (S.D. $=4.48)$ on the science ACT assessment, while Latino children who completed at least one AP/Honors science course earned a mean score of 21.33 (S.D. $=4.13$ ) on the same assessment. Tukey's post hoc test determined the mean difference in science ACT performance between low-income White and Latino students who completed at least one AP/Honors science course (3.57) to be statistically significant at the 0.01 level of significance. In regards to social studies/reading, White children who completed at least one AP/Honors social studies course earned a mean score of 23.51 $(\mathrm{S} . \mathrm{D} .=5.61)$ on the reading ACT assessment, while Latino children who completed at least one AP/Honors social studies course earned a mean score of 19.78 (S.D. $=5.00)$ on the reading ACT assessment. Tukey's post hoc test determined the mean difference in reading ACT performance between low-income White and Latino students who completed at least one AP/Honors social studies course (3.73) to be statistically significant at the 0.01 level of significance.

To address the final component of the research question, the ACT performance of Latino students who completed at least one AP/Honors course was compared to the ACT performance of Black students who completed at least one AP/Honors course. Among non low-income students, Latino children who completed at least one AP/Honors English 
course earned a mean score of $25.34($ S.D. $=5.32)$ on the English ACT assessment, while Black children who completed at least one AP/Honors English course earned a mean score of $23.66($ S.D. $=5.27)$ on the English ACT assessment. Tukey's post hoc test determined the mean difference in English ACT performance between non low-income Latino and Black students who completed at least one AP/Honors English course (1.68) to be statistically significant at the 0.01 level of significance. In regards to mathematics, Latino children who completed at least one AP/Honors mathematics course earned a mean score of $26.58($ S.D. $=4.60)$ on the mathematics ACT assessment, while Black children who completed at least one AP/Honors mathematics course earned a mean score of 24.59 (S.D. $=4.74$ ) on the mathematics ACT assessment. Tukey's post hoc test determined the mean difference in mathematics ACT performance between non lowincome Latino and Black students who completed at least one AP/Honors mathematics course (1.99) to be statistically significant at the 0.01 level of significance. In science, Latino children who completed at least one AP/Honors science course earned a mean score of $24.30($ S.D. $=4.64)$ on the science ACT assessment, while Black children who completed at least one AP/Honors science course earned a mean score of 22.98 (S.D. $=$ 4.32) on the same assessment. Tukey's post hoc test determined the mean difference in science ACT performance between non low-income Latino and Black students who completed at least one AP/Honors science course (1.32) to be statistically significant at the 0.01 level of significance. In regards to social studies/reading, Latino children who completed at least one AP/Honors social studies course earned a mean score of 22.92 $(\mathrm{S} . \mathrm{D} .=5.76)$ on the reading $\mathrm{ACT}$ assessment, while Black children who completed at least one AP/Honors social studies course earned a mean score of $21.32($ S.D. $=5.43)$ on 
the reading ACT assessment. Tukey's post hoc test determined the mean difference in reading ACT performance between non low-income Latino and Black students who completed at least one AP/Honors social studies course (1.60) to be statistically significant at the 0.01 level of significance.

Among low-income students, Latino children who completed at least one AP/Honors English course earned a mean score of 20.46 (S.D. = 5.08) on the English ACT assessment, while Black children who completed at least one AP/Honors English course earned a mean score of $19.34($ S.D. $=5.08)$ on the English ACT assessment. Tukey's post hoc test determined the mean difference in English ACT performance between low-income Latino and Black students who completed at least one AP/Honors English course (1.12) to be statistically significant at the 0.01 level of significance. In regards to mathematics, Latino children who completed at least one AP/Honors mathematics course earned a mean score of $23.12($ S.D. $=4.35)$ on the mathematics ACT assessment, while Black children who completed at least one AP/Honors mathematics course earned a mean score of 20.74 (S.D. $=4.40)$ on the mathematics ACT assessment. Tukey's post hoc test determined the mean difference in mathematics ACT performance between low-income Latino and Black students who completed at least one AP/Honors mathematics course (2.38) to be statistically significant at the 0.01 level of significance. In science, Latino children who completed at least one AP/Honors science course earned a mean score of 21.33 (S.D. $=4.13)$ on the science ACT assessment, while Black children who completed at least one AP/Honors science course earned a mean score of 20.00 $($ S.D. $=4.09)$ on the same assessment. Tukey's post hoc test determined the mean difference in science ACT performance between low-income Latino and Black students 
who completed at least one $\mathrm{AP} /$ Honors science course (1.33) to be statistically significant at the 0.01 level of significance. In regards to social studies/reading, Latino children who completed at least one AP/Honors social studies course earned a mean score of 19.78 $(\mathrm{S} . \mathrm{D} .=5.00)$ on the reading ACT assessment, while Black children who completed at least one AP/Honors social studies course earned a mean score of $18.91($ S.D. $=5.01)$ on the reading ACT assessment. Tukey's post hoc test determined the mean difference in reading ACT performance between low-income Latino and Black students who completed at least one AP/Honors social studies course (0.87) to be statistically significant at the 0.01 level of significance.

\section{Research Question 3}

The third research question examined the differences in ACT scores between (a) Black students who have completed at least one AP/Honors (English, mathematics, science, and/or social studies) course and those who have not, (b) Latino students who have completed at least one AP/Honors (English, mathematics, science, and/or social studies) course and those who have not, and (c) White students who have completed at least one AP/Honors (English, mathematics, science, and/or social studies) course and those who have not. To satisfy the first component of this research question, data were filtered to include only African American students. In all four of the content areas studied (English, mathematics, science, and social studies/reading), ACT mean scores varied between Black students who completed at least one AP/Honors course and Black students who only completed lower track courses. The means and standard deviations are presented in Table 17. 
Table 17

Differences in Black Students' ACT Mean Scores by Content Area

\begin{tabular}{lrrr}
\hline & $\mathrm{N}$ & $M$ & \multicolumn{1}{c}{$S D$} \\
\hline English & & & \\
Participated in AP/Honors English course(s) & 2,996 & 20.61 & 5.50 \\
Participated in lower track English course(s) & 21,557 & 14.91 & 4.93 \\
& & & \\
Mathematics & & & \\
$\quad$ Participated in AP/Honors mathematics course(s) & 1,368 & 22.23 & 4.91 \\
$\quad$ Participated in lower track mathematics course(s) & 23,195 & 16.65 & 3.14 \\
& & & \\
Science & & & \\
Participated in AP/Honors science course(s) & 1,527 & 21.07 & 4.41 \\
Participated in lower track science course(s) & 23,006 & 16.61 & 3.99 \\
& & & \\
Reading & & & \\
$\quad$ Participated in AP/Honors social studies course(s) & 3,694 & 19.76 & 5.29 \\
Participated in lower track social studies course(s) & 20,849 & 15.36 & 4.22 \\
\hline
\end{tabular}

Data were screened to ensure that assumptions of factorial ANOVA were fulfilled, and a univariate ANOVA was conducted for each content area studied. The summary results of ANOVA are presented in Table 18.

Table 18

Differences Between Black Students Who Completed at Least One AP/Honors Course and Those Who Did Not

\begin{tabular}{lcccc}
\hline & $\mathrm{F}\left(\mathrm{df}_{\mathrm{b}}, \mathrm{df}_{\mathrm{w}}\right)^{\mathrm{a}}$ & $\mathrm{F}$ & $\mathrm{p}$ & $\mathrm{ES}$ \\
\hline English & $(1,24,551)$ & $3,427.22$ & $<.001^{\mathrm{b}}$ & 0.122 \\
Mathematics & $(1,24,561)$ & $3,774.83$ & $<.001$ & 0.133 \\
Science & $(1,24,531)$ & $1,767.41$ & $<.001$ & 0.067 \\
Social Studies/ Reading & $(1,24,541)$ & $3,146.24$ & $<.001$ & 0.114 \\
\hline
\end{tabular}

${ }^{\mathrm{a}} \mathrm{df}_{\mathrm{b}}$ - degrees of freedom between groups, $\mathrm{df}_{\mathrm{w}}-$ degrees of freedom within groups

${ }^{\mathrm{b}}$ Significant at 0.01 level of significance 
Black students who completed at least one AP/Honors English course earned a mean score of 20.61 (S.D. $=5.50)$ on the English ACT assessment, while Black students who completed only lower track English courses earned a mean score of 14.91 (S.D. = 4.93) on the English ACT assessment. The ANOVA revealed a statistically significant difference in English ACT performance between Black students who completed at least one AP/Honors English course and Black students who did not, $F(1,24,551)=3,427.22$, $p<.001, \eta^{2}=0.122$. Among African American students, the effect size revealed a medium treatment effect with approximately $12 \%$ of the variance in English ACT scores attributable to participation in at least one AP/Honors English course.

Black students who completed at least one AP/Honors mathematics course earned a mean score of 22.23 (S.D. $=4.91$ ) on the mathematics ACT assessment, while Black students who completed only lower track mathematics courses earned a mean score of $16.65($ S.D. $=3.14)$ on the same assessment. The ANOVA revealed a statistically significant difference in mathematics ACT performance between Black students who completed at least one AP/Honors mathematics course and those who did not, $F(1$, $24,561)=3,774.83, p<.001, \eta^{2}=0.133$. The effect size revealed a medium treatment effect among African American students with approximately $13 \%$ of the variance in mathematics ACT scores attributable to participation in at least one AP/Honors mathematics course.

On the science ACT assessment, Black students who completed at least one AP/Honors science course earned a mean score of 21.07 (S.D. = 4.41), whereas, Black students who completed only lower track science courses earned a mean score of 16.61 (S.D. = 3.99). The ANOVA revealed a statistically significant difference in science ACT 
performance between Black students who completed at least one AP/Honors science course and those who did not, $F(1,24,531)=1,767.41, p<.001, \eta^{2}=0.067$. The effect size revealed a small treatment effect among African American students with approximately $7 \%$ of the variance in science ACT scores attributable to participation in at least one AP/Honors science course.

Black students who completed at least one AP/Honors social studies course earned a mean score of $19.76($ S.D. $=5.29)$ on the reading ACT assessment, while Black students who completed only lower track social studies courses earned a mean score of 15.36 (S.D. $=4.22$ ) on the reading ACT assessment. The ANOVA revealed a statistically significant difference in reading ACT performance between Black students who completed at least one AP/Honors social studies course and Black students who did not, $F(1,24,541)=3,146.24, p<.001, \eta^{2}=0.114$. The effect size revealed a medium treatment effect among African American students with approximately $11 \%$ of the variance in reading $\mathrm{ACT}$ scores attributable to participation in at least one AP/Honors social studies course.

To satisfy the second component of this research question, data were filtered to include only Latino students. In all four of the content areas studied (English, mathematics, science, and social studies/reading), ACT mean scores varied between Latino students who completed at least one AP/Honors course and Latino students who only completed lower track courses. The means and standard deviations are presented in Table 19. 
Table 19

Differences in Latino Students' ACT Mean Scores by Content Area

\begin{tabular}{lrrr}
\hline & $\mathrm{N}$ & $M$ & \multicolumn{1}{c}{$S D$} \\
\hline English & & & \\
Participated in AP/Honors English course(s) & 4,673 & 21.92 & 5.62 \\
$\quad$ Participated in lower track English course(s) & 24,447 & 16.29 & 5.26 \\
& & & \\
Mathematics & & & \\
$\quad$ Participated in AP/Honors mathematics course(s) & 2,886 & 24.53 & 4.76 \\
$\quad$ Participated in lower track mathematics course(s) & 26,314 & 17.90 & 3.67 \\
& & & \\
Science & & & \\
Participated in AP/Honors science course(s) & 3,184 & 22.45 & 4.56 \\
Participated in lower track science course(s) & 25,989 & 17.76 & 4.26 \\
& & & \\
Reading & & & \\
$\quad$ Participated in AP/Honors social studies course(s) & 6,386 & 20.97 & 5.51 \\
Participated in lower track social studies course(s) & 22,788 & 16.08 & 4.62 \\
\hline
\end{tabular}

Data were screened to ensure that assumptions of factorial ANOVA were fulfilled, and a univariate ANOVA was conducted for each content area studied. The summary results of ANOVA are presented in Table 20.

Table 20

Differences Between Latino Students Who Completed at Least One AP/Honors Course and Those Who Did Not

\begin{tabular}{lcccc}
\hline & $\mathrm{F}\left(\mathrm{df}_{\mathrm{b}}, \mathrm{df}_{\mathrm{w}}\right)^{\mathrm{a}}$ & $\mathrm{F}$ & $\mathrm{p}$ & $\mathrm{ES}$ \\
\hline English & $(1,29,118)$ & $4,398.32$ & $<.001^{\mathrm{b}}$ & 0.131 \\
Mathematics & $(1,29,198)$ & $7,950.83$ & $<.001$ & 0.214 \\
Science & $(1,29,171)$ & $3,368.60$ & $<.001$ & 0.104 \\
Social Studies/Reading & $(1,29,172)$ & $5,106.48$ & $<.001$ & 0.149 \\
\hline
\end{tabular}

${ }^{\mathrm{a}} \mathrm{df}_{\mathrm{b}}$ - degrees of freedom between groups, $\mathrm{df}_{\mathrm{w}}-$ degrees of freedom within groups

${ }^{\mathrm{b}}$ Significant at 0.01 level of significance 
Latino students who completed at least one AP/Honors English course earned a mean score of 21.92 (S.D. $=5.62$ ) on the English ACT assessment, while Latino students who completed only lower track English courses earned a mean score of 16.29 (S.D. $=$ 5.26) on the English ACT assessment. The ANOVA revealed a statistically significant difference in English ACT performance between Latino students who completed at least one AP/Honors English course and Latino students who did not, $F(1,29,118)=4,398.32$, $p<.001, \eta^{2}=0.131$. The effect size revealed a medium treatment effect among Latino students with approximately $13 \%$ of the variance in English ACT scores attributable to participation in at least one AP/Honors English course.

Latino students who completed at least one AP/Honors mathematics course earned a mean score of $24.53($ S.D. $=4.76)$ on the mathematics ACT assessment, while Latino students who completed only lower track mathematics courses earned a mean score of $17.90($ S.D. $=3.67)$ on the same assessment. The ANOVA revealed a statistically significant difference in mathematics ACT performance between Latino students who completed at least one AP/Honors mathematics course and those who did not, $F(1,29,198)=7,950.83, p<.001, \eta^{2}=0.214$. The effect size revealed a medium treatment effect among Latino students with approximately $21 \%$ of the variance in mathematics ACT scores attributable to participation in at least one AP/Honors mathematics course.

On the science ACT assessment, Latino students who completed at least one AP/Honors science course earned a mean score of 22.45 (S.D. $=4.56)$, whereas Latino students who completed only lower track science courses earned a mean score of 17.76 (S.D. $=4.26)$. The ANOVA revealed a statistically significant difference in science ACT 
performance between Latino students who completed at least one AP/Honors science course and those who did not, $F(1,29,171)=3,368.60, p<.001, \eta^{2}=0.104$. The effect size revealed a medium treatment effect among Latino students with approximately $10 \%$ of the variance in science ACT scores attributable to participation in at least one AP/Honors science course.

Latino students who completed at least one AP/Honors social studies course earned a mean score of $20.97($ S.D. $=5.51)$ on the reading ACT assessment, while Latino students who completed only lower track social studies courses earned a mean score of 16.08 (S.D. $=4.62$ ) on the reading ACT assessment. The ANOVA revealed a statistically significant difference in reading ACT performance between Latino students who completed at least one AP/Honors social studies course and Latino students who did not, $F(1,29,172)=5,106.48, p<.001, \eta^{2}=0.149$. The effect size revealed a medium treatment effect among Latino students with approximately $15 \%$ of the variance in reading ACT scores attributable to participation in at least one AP/Honors social studies course.

To satisfy the final component of this research question, data were filtered to include only White students. In all four of the content areas studied (English, mathematics, science, and social studies/reading), ACT mean scores varied between White students who completed at least one AP/Honors course and White students who only completed lower track courses. The means and standard deviations are presented in Table 21. 
Table 21

Differences in White Students' ACT Mean Scores by Content Area

\begin{tabular}{lccc}
\hline & $\mathrm{N}$ & $M$ & $S D$ \\
\hline English & & & \\
Participated in AP/Honors English course(s) & 13,785 & 27.93 & 4.68 \\
$\quad$ Participated in lower track English course(s) & 66,831 & 20.32 & 5.95 \\
& & & \\
Mathematics & & & \\
$\quad$ Participated in AP/Honors mathematics course(s) & 14,407 & 29.01 & 4.04 \\
$\quad$ Participated in lower track mathematics course(s) & 66,212 & 20.38 & 4.47 \\
& & & \\
Science & & & \\
Participated in AP/Honors science course(s) & 12,503 & 26.97 & 4.37 \\
$\quad$ Participated in lower track science course(s) & 68,096 & 20.81 & 4.94 \\
& & & \\
Reading & & & \\
$\quad$ Participated in AP/Honors social studies course(s) & 22,540 & 25.57 & 5.54 \\
Participated in lower track social studies course(s) & 58,066 & 19.66 & 5.63 \\
\hline
\end{tabular}

Data were screened to ensure that assumptions of factorial ANOVA were fulfilled, and a univariate ANOVA was conducted for each content area studied. The summary results of ANOVA are presented in Table 22.

Table 22

Differences Between White Students Who Completed at Least One AP/Honors Course and Those Who Did Not

\begin{tabular}{lcccc}
\hline & $\mathrm{F}\left(\mathrm{df}_{\mathrm{b}}, \mathrm{df}_{\mathrm{w}}\right)^{\mathrm{a}}$ & $\mathrm{F}$ & $\mathrm{p}$ & $\mathrm{ES}$ \\
\hline English & $(1,80,614)$ & $20,004.53$ & $<.001^{\mathrm{b}}$ & 0.199 \\
Mathematics & $(1,80,617)$ & $45,691.90$ & $<.001$ & 0.362 \\
Science & $(1,80,597)$ & $16,994.94$ & $<.001$ & 0.174 \\
Social Studies/Reading & $(1,80,604)$ & $18,066.12$ & $<.001$ & 0.183 \\
\hline
\end{tabular}

${ }^{\mathrm{a}} \mathrm{df}_{\mathrm{b}}$ - degrees of freedom between groups, $\mathrm{df}_{\mathrm{w}}-$ degrees of freedom within groups

${ }^{\mathrm{b}}$ Significant at 0.01 level of significance 
White students who completed at least one AP/Honors English course earned a mean score of 27.93 (S.D. $=4.68$ ) on the English ACT assessment, while White students who completed only lower track English courses earned a mean score of 20.32 (S.D. $=$ 5.95) on the English ACT assessment. The ANOVA revealed a statistically significant difference in English ACT performance between White students who completed at least one $\mathrm{AP} /$ Honors English course and White students who did not, $F(1,80,614)=$ 20,004.53, $p<.001, \eta^{2}=0.199$. Among White students, the effect size revealed a medium treatment effect with approximately $20 \%$ of the variance in English ACT scores attributable to participation in at least one AP/Honors English course.

White students who completed at least one AP/Honors mathematics course earned a mean score of 29.01 (S.D. $=4.04$ ) on the mathematics ACT assessment, while White students who completed only lower track mathematics courses earned a mean score of 20.38 (S.D. $=4.47)$ on the same assessment. The ANOVA revealed a statistically significant difference in mathematics ACT performance between White students who completed at least one AP/Honors mathematics course and those who did not, $F(1$, $80,617)=45,691.90, p<.001, \eta^{2}=0.362$. The effect size revealed a large treatment effect among White students with approximately $36 \%$ of the variance in mathematics ACT scores attributable to participation in at least one AP/Honors mathematics course.

On the science ACT assessment, White students who completed at least one AP/Honors science course earned a mean score of 26.97 (S.D. $=4.37$ ), whereas White students who completed only lower track science courses earned a mean score of 20.81 $($ S.D. $=4.94)$. The ANOVA revealed a statistically significant difference in science ACT performance between White students who completed at least one AP/Honors science 
course and those who did not, $F(1,80,597)=16,994.94, p<.001, \eta^{2}=0.174$. The effect size revealed a medium treatment effect among White students with approximately $17 \%$ of the variance in science ACT scores attributable to participation in at least one AP/Honors science course.

White students who completed at least one AP/Honors social studies course earned a mean score of 25.57 (S.D. $=5.54$ ) on the reading ACT assessment, while White students who completed only lower track social studies courses earned a mean score of 19.66 (S.D. $=5.63)$ on the reading ACT assessment. The ANOVA revealed a statistically significant difference in reading ACT performance between White students who completed at least one AP/Honors social studies course and White students who did not, $F(1,80,604)=18,066.12, p<.001, \eta^{2}=0.183$. The effect size revealed a medium treatment effect among White students with approximately $18 \%$ of the variance in reading ACT scores attributable to participation in at least one AP/Honors social studies course.

\section{Research Question 4}

The fourth research question examined the differences in ACT scores between low-income students and non low-income students who have completed at least one AP/Honors (English, mathematics, science, and/or social studies) course. For the purposes of this research question, all students who completed an AP/Honors course were evaluated, and treatment groups were defined through participation or non-participation in the National School Lunch Program. When comparing the ACT performance of lowincome students who completed at least one AP/Honors course to the ACT performance of non low-income students who completed at least on AP/Honors course, results indicated variability between treatment means in all four of the content areas studied 
(English, mathematics, science, and social studies/reading). The means and standard deviations are presented in Table 23.

Table 23

Differences Between Low-Income and Non Low-Income Students' ACT Mean Scores by Content Area

\begin{tabular}{lrrr}
\hline & $\mathrm{N}$ & $M$ & $S D$ \\
\hline English & & & \\
$\quad$ Low-Income & 7,483 & 21.44 & 5.64 \\
$\quad$ Non Low-Income & 17,017 & 27.85 & 4.81 \\
Mathematics & & & \\
$\quad$ Low-Income & 4,287 & 24.21 & 4.98 \\
$\quad$ Non Low-Income & 17,917 & 29.00 & 4.19 \\
Science & & & \\
$\quad$ Low-Income & 4,799 & 22.43 & 4.69 \\
$\quad$ Non Low-Income & 15,858 & 26.84 & 4.49 \\
Reading & & & \\
$\quad$ Low-Income & 9,566 & 20.71 & 5.51 \\
$\quad$ Non Low-Income & 27,689 & 25.32 & 5.67 \\
\hline
\end{tabular}

Data were screened to ensure that assumptions of factorial ANOVA were fulfilled, and a univariate ANOVA was conducted for each content area studied. The summary results of the ANOVA are presented in Table 24.

Table 24

Differences Between Low-Income and Non Low-Income Students Who Completed at Least One AP/Honors Course

\begin{tabular}{lcccc}
\hline & $\mathrm{F}\left(\mathrm{df}_{\mathrm{b}}, \mathrm{df}_{\mathrm{w}}\right)^{\mathrm{a}}$ & $\mathrm{F}$ & $\mathrm{p}$ & $\mathrm{ES}$ \\
\hline English & $(1,24,498)$ & $8,268.08$ & $<.001^{\mathrm{b}}$ & 0.252 \\
Mathematics & $(1,22,202)$ & $4,199.23$ & $<.001$ & 0.159 \\
Science & $(1,20,655)$ & $3,480.81$ & $<.001$ & 0.144 \\
Social Studies/Reading & $(1,37,253)$ & $4,763.90$ & $<.001$ & 0.113 \\
\hline
\end{tabular}

${ }^{\mathrm{a}} \mathrm{df}_{\mathrm{b}}$ - degrees of freedom between groups, $\mathrm{df}_{\mathrm{w}}-$ degrees of freedom within groups

${ }^{\mathrm{b}}$ Significant at 0.01 level of significance 
Low-income students who completed at least one AP/Honors English course earned a mean score of 21.44 (S.D. = 5.64) on the English ACT assessment, while non low-income students who completed at least one AP/Honors English course earned a mean score of $27.85($ S.D. $=4.81)$ on the English ACT assessment. The ANOVA revealed a statistically significant difference in English ACT performance between lowincome students who completed at least one AP/Honors English course and non lowincome students who completed at least one AP/Honors English course, $F(1,24,498)=$ $8,268.08, p<.001, \eta^{2}=0.252$. Among students who completed at least one AP/Honors English course, the effect size revealed a large treatment effect with approximately $25 \%$ of the variance in English ACT scores attributable to participation in the National School Lunch Program.

Low-income students who completed at least one AP/Honors mathematics course earned a mean score of $24.21($ S.D. $=4.98)$ on the mathematics ACT assessment, while non low-income students who completed at least one AP/Honors mathematics course earned a mean score of $29.00($ S.D. $=4.19)$ on the same assessment. The ANOVA revealed a statistically significant difference in mathematics ACT performance between low-income students who completed at least one AP/Honors mathematics course and non low-income students who completed at least one AP/Honors mathematics course, $F(1$, $22,202)=4,199.23, p<.001, \eta^{2}=0.159$. Among students who completed at least one $\mathrm{AP} /$ Honors mathematics course, the effect size revealed a medium treatment effect with approximately $16 \%$ of the variance in mathematics ACT scores attributable to participation in the National School Lunch Program. 
On the science ACT assessment, low-income students who completed at least one AP/Honors science course earned a mean score of 22.43 (S.D. = 4.69), whereas non lowincome students who completed at least one AP/Honors science course earned a mean score of $26.84($ S.D. $=4.49)$. The ANOVA revealed a statistically significant difference in science ACT performance between low-income students who completed at least one AP/Honors science course and non low-income students who completed at least one AP/Honors science course, $F(1,20,655)=3,480.81, p<.001, \eta^{2}=0.144$. Among students who completed at least one AP/Honors science course, the effect size revealed a medium treatment effect with approximately $14 \%$ of the variance in science ACT scores attributable to participation in the National School Lunch Program.

Low-income students who completed at least one AP/Honors social studies course earned a mean score of 20.71 (S.D. $=5.51$ ) on the reading ACT assessment, while non low-income students who completed at least one AP/Honors social studies course earned a mean score of 25.32 (S.D. $=5.67$ ) on the reading ACT assessment. The ANOVA revealed a statistically significant difference in reading ACT performance between lowincome students who completed at least one AP/Honors social studies course and non low-income students who completed at least one AP/Honors social studies course, $F(1$, $37,253)=4,763.90, p<.001, \eta^{2}=0.113$. Among students who completed at least one AP/Honors social studies course, the effect size revealed a medium treatment effect with approximately $11 \%$ of the variance in reading ACT scores attributable to participation in the National School Lunch Program. 


\section{Research Question 5}

The final research question examined the differences in ACT scores between (a) low-income students who have completed at least one AP/Honors (English, mathematics, science, and/or social studies) course and those who have not, and (b) non low-income students who have completed at least one AP/Honors (English, mathematics, science, and/or social studies) course and those who have not. To satisfy the first component of this research question, data was filtered to include only low-income students. In all four of the content areas studied (English, mathematics, science, and social studies/reading), ACT mean scores varied between low-income students who completed at least one AP/Honors course and low-income students who only completed lower track courses. The means and standard deviations are presented in Table 25.

Table 25

Differences in Low-Income Students' ACT Mean Scores by Content Area

\begin{tabular}{lrrr}
\hline & $\mathrm{N}$ & $M$ & \multicolumn{1}{c}{$S D$} \\
\hline English & & & \\
$\quad$ Participated in AP/Honors English course(s) & 7,483 & 21.44 & 5.64 \\
$\quad$ Participated in lower track English course(s) & 50,121 & 15.81 & 5.27 \\
& & & \\
Mathematics & & & \\
$\quad$ Participated in AP/Honors mathematics course(s) & 4,287 & 24.21 & 4.98 \\
$\quad$ Participated in lower track mathematics course(s) & 53,387 & 17.44 & 3.57 \\
& & & \\
Science & & & \\
$\quad$ Participated in AP/Honors science course(s) & 4,799 & 22.43 & 4.69 \\
$\quad$ Participated in lower track science course(s) & 52,817 & 17.38 & 4.27 \\
& & & \\
Reading & & & \\
$\quad$ Participated in AP/Honors social studies course(s) & 9,566 & 20.71 & 5.51 \\
Participated in lower track social studies course(s) & 48,051 & 16.14 & 4.74 \\
\hline
\end{tabular}


Data were screened to ensure that assumptions of factorial ANOVA were fulfilled, and a univariate ANOVA was conducted for each content area studied. The summary results of ANOVA are presented in Table 26.

Table 26

Differences Between Low-Income Students Who Completed at Least One AP/Honors Course and Those Who Did Not

\begin{tabular}{lcrcc}
\hline & $\mathrm{F}\left(\mathrm{df}_{\mathrm{b}}, \mathrm{df}_{\mathrm{w}}\right)^{\mathrm{a}}$ & $\mathrm{F}$ & $\mathrm{p}$ & $\mathrm{ES}$ \\
\hline English & $(1,57,602)$ & $7,308.63$ & $<.001^{\mathrm{b}}$ & 0.113 \\
Mathematics & $(1,57,672)$ & $13,328.33$ & $<.001$ & 0.188 \\
Science & $(1,57,616)$ & $6,054.15$ & $<.001$ & 0.095 \\
Social Studies/Reading & $(1,57,615)$ & $7,000.90$ & $<.001$ & 0.108 \\
\hline
\end{tabular}

${ }^{\mathrm{a}} \mathrm{df}_{\mathrm{b}}$ - degrees of freedom between groups, $\mathrm{df}_{\mathrm{w}}-$ degrees of freedom within groups

${ }^{\mathrm{b}}$ Significant at 0.01 level of significance

Low-income students who completed at least one AP/Honors English course earned a mean score of 21.44 (S.D. $=5.64)$ on the English ACT assessment, while lowincome students who completed only lower track English courses earned a mean score of $15.81($ S.D. $=5.27)$ on the English ACT assessment. The ANOVA revealed a statistically significant difference in English ACT performance between low-income students who completed at least one AP/Honors English course and low-income students who did not, $F(1,57,602)=7,308.63, p<.001, \eta^{2}=0.113$. Among low-income students, the effect size revealed a medium treatment effect with approximately $11 \%$ of the variance in English ACT scores attributable to participation in at least one $\mathrm{AP} /$ Honors English course. 
Low-income students who completed at least one AP/Honors mathematics course earned a mean score of 24.21 (S.D. $=4.98)$ on the mathematics ACT assessment, while low-income students who completed only lower track mathematics courses earned a mean score of $17.44($ S.D. $=3.57)$ on the same assessment. The ANOVA revealed a statistically significant difference in mathematics ACT performance between low-income students who completed at least one AP/Honors mathematics course and those who did not, $F(1,57,672)=13,328.33, p<.001, \eta^{2}=0.188$. The effect size revealed a medium treatment effect among low-income students with approximately $19 \%$ of the variance in mathematics ACT scores attributable to participation in at least one AP/Honors mathematics course.

On the science ACT assessment, low-income students who completed at least one AP/Honors science course earned a mean score of 22.43 (S.D. $=4.69)$, whereas lowincome students who completed only lower track science courses earned a mean score of 17.38 (S.D. $=4.27)$. The ANOVA revealed a statistically significant difference in science ACT performance between low-income students who completed at least one AP/Honors science course and those who did not, $F(1,57,614)=6,054.15, p<.001, \eta^{2}=$ 0.095. Among low-income students, the effect size revealed a medium treatment effect with approximately $10 \%$ of the variance in science ACT scores attributable to participation in at least one $\mathrm{AP} /$ Honors science course.

Low-income students who completed at least one AP/Honors social studies course earned a mean score of 20.71 (S.D. $=5.51)$ on the reading ACT assessment, while lowincome students who completed only lower track social studies courses earned a mean score of $16.14($ S.D. $=4.74)$ on the reading ACT assessment. The ANOVA revealed a 
statistically significant difference in reading ACT performance between low-income students who completed at least one AP/Honors social studies course and low-income students who did not, $F(1,57,615)=7,000.90, p<.001, \eta^{2}=0.108$. Among low-income students, the effect size revealed a medium treatment effect with approximately $11 \%$ of the variance in reading ACT scores attributable to participation in at least one AP/Honors social studies course.

To satisfy the second component of this research question, data were filtered to include only non low-income students. In all four of the content areas studied (English, mathematics, science, and social studies/reading), ACT mean scores varied between non low-income students who completed at least one AP/Honors course and non low-income students who only completed lower track courses. The means and standard deviations are presented in Table 27.

Table 27

Differences in Non Low-Income Students' ACT Mean Scores by Content Area

\begin{tabular}{lccc}
\hline & $\mathrm{N}$ & $M$ & $S D$ \\
\hline English & & & \\
Participated in AP/Honors English course(s) & 17,017 & 27.85 & 4.81 \\
$\quad$ Participated in lower track English course(s) & 69,820 & 20.41 & 5.94 \\
Mathematics & & & \\
$\quad$ Participated in AP/Honors mathematics course(s) & 17,917 & 29.00 & 4.19 \\
$\quad$ Participated in lower track mathematics course(s) & 68,973 & 20.41 & 4.48 \\
& & & \\
Science & 15,858 & 26.84 & 4.49 \\
$\quad$ Participated in AP/Honors science course(s) & 71,010 & 20.81 & 4.94 \\
$\quad$ Participated in lower track science course(s) & & & \\
Reading & & & \\
Participated in AP/Honors social studies course(s) & 27,689 & 25.32 & 5.67 \\
Participated in lower track social studies course(s) & 59,190 & 19.48 & 5.63 \\
\hline
\end{tabular}


Data were screened to ensure that assumptions of factorial ANOVA were fulfilled, and a univariate ANOVA was conducted for each content area studied. The summary results of ANOVA are presented in Table 28.

Table 28

Differences Between Non Low-Income Students Who Completed at Least One AP/Honors Course and Those Who Did Not

\begin{tabular}{lcccc}
\hline & $\mathrm{F}\left(\mathrm{df}_{\mathrm{b}}, \mathrm{df}_{\mathrm{w}}\right)^{\mathrm{a}}$ & $\mathrm{F}$ & $\mathrm{p}$ & $\mathrm{ES}$ \\
\hline English & $(1,86,835)$ & $23,009.36$ & $<.001^{\mathrm{b}}$ & 0.209 \\
Mathematics & $(1,86,888)$ & $53,659.68$ & $<.001$ & 0.382 \\
Science & $(1,86,866)$ & $19,941.26$ & $<.001$ & 0.187 \\
Social Studies/Reading & $(1,86,877)$ & $20,188.99$ & $<.001$ & 0.189 \\
\hline
\end{tabular}

${ }^{\mathrm{a}} \mathrm{df}_{\mathrm{b}}$ - degrees of freedom between groups, $\mathrm{df}_{\mathrm{w}}-$ degrees of freedom within groups

${ }^{\mathrm{b}}$ Significant at 0.01 level of significance

Non low-income students who completed at least one AP/Honors English course earned a mean score of 27.85 (S.D. $=4.81)$ on the English ACT assessment, while non low-income students who completed only lower track English courses earned a mean score of $20.41($ S.D. $=5.94)$ on the English ACT assessment. The ANOVA revealed a statistically significant difference in English ACT performance between non low-income students who completed at least one AP/Honors English course and non low-income students who did not, $F(1,86,835)=23,009.36, p<.001, \eta^{2}=0.209$. Among non lowincome students, the effect size revealed a medium treatment effect with approximately $21 \%$ of the variance in English ACT scores attributable to participation in at least one AP/Honors English course.

Non low-income students who completed at least one AP/Honors mathematics course earned a mean score of $29.00($ S.D. $=4.19)$ on the mathematics ACT assessment, 
while non low-income students who completed only lower track mathematics courses earned a mean score of $20.41($ S.D. $=4.48)$ on the same assessment. The ANOVA revealed a statistically significant difference in mathematics ACT performance between non low-income students who completed at least one AP/Honors mathematics course and those who did not, $F(1,86,888)=53,659.68, p<.001, \eta^{2}=0.382$. The effect size revealed a large treatment effect among non low-income students with approximately $38 \%$ of the variance in mathematics ACT scores attributable to participation in at least one AP/Honors mathematics course.

On the science ACT assessment, non low-income students who completed at least one AP/Honors science course earned a mean score of 26.84 (S.D. $=4.49)$, whereas non low-income students who completed only lower track science courses earned a mean score of 20.81 (S.D. = 4.94). The ANOVA revealed a statistically significant difference in science ACT performance between non low-income students who completed at least one AP/Honors science course and those who did not, $F(1,86,866)=19,941.26, p<.001$, $\eta^{2}=0.187$. Among non low-income students, the effect size revealed a medium treatment effect with approximately $19 \%$ of the variance in science ACT scores attributable to participation in at least one AP/Honors science course.

Non low-income students who completed at least one AP/Honors social studies course earned a mean score of $25.32($ S.D. $=5.67)$ on the reading ACT assessment, while non low-income students who completed only lower track social studies courses earned a mean score of $19.48($ S.D. $=5.63)$ on the reading ACT assessment. The ANOVA revealed a statistically significant difference in reading ACT performance between non low-income students who completed at least one AP/Honors social studies course and 
non low-income students who did not, $F(1,86,877)=20,188.99, p<.001, \eta^{2}=0.189$. Among non low-income students, the effect size revealed a medium treatment effect with approximately $19 \%$ of the variance in reading ACT scores attributable to participation in at least one AP/Honors social studies course.

\section{Summary}

This chapter provided an analysis of quantitative data in relation to five research questions that sought to examine the relationship and differences between students who have completed AP/Honors courses and those who have not in traditional Illinois public high schools. In doing so, students' socioeconomic status, race, and AP/Honors course placement were considered. Regardless of socioeconomic status or race, and across all content areas studied (English, mathematics, science, social studies/reading), students who participated in AP/Honors courses performed significantly better on ACT tests than students who completed only lower track classes. Furthermore, effect sizes generally indicated medium to large treatment effects when comparing the ACT performance of students who completed at least one AP/Honors course to that of students who did not. Based upon the data analysis, AP/Honors course placement appears advantageous to all students, regardless of socioeconomic status or race, across all content areas (i.e., English, mathematics, science, and social studies). The final chapter summarizes the findings, implications, and conclusions that can be drawn from the data analysis contained in this chapter. 


\section{CHAPTER V}

\section{FINDINGS, IMPLICATIONS, AND CONCLUSIONS}

The theoretical framework shaping this study suggests that disparities in academic achievement among various student groups are a result of a system of schooling that engenders unequal educational opportunities for all children. More specifically, in most American schools, tracking policies and practices sort students based upon perceived academic ability levels and, subsequently, provide children with varying degrees of curricular and instructional rigor (Burris \& Garrity, 2008; Lucas, 1999; Yonezawa, Wells, \& Serna, 2002). With research demonstrating that low-track classes provide students with less rigorous curricula (Oakes \& Wells, 1998; Darling-Hammond, 2010; Eckstrom \& Villages, 1991; Garoman, 1998; Oakes, 2005) and contain disproportionately high percentages of low-income and minority children (Dornbusch, 1994; Oakes, 2005; Oakes, Garoman, \& Page, 1992; Burris \& Welner, 2005; Wells \& Serna, 1996; Yonezawa, Wells, \& Serna, 2002), some contemporary educators have questioned whether achievement gaps can be more accurately defined as opportunity gaps. To further explore the issue of achievement equity as it relates to educational opportunities, this study examined the relationship and differences between students who completed Advanced Placement (AP)/Honors courses and those who did not in traditional Illinois public high schools. 


\section{Discussion of Findings}

Consistent with national trends, low-income and minority students across the state of Illinois were overrepresented in low-track classes and underrepresented in high-track classes during the 2012-2013 school year. While $40.1 \%$ of the Illinois children studied were considered low-income, only $30.6 \%$ of the state's AP/Honors English course participants were low-income students, $19.3 \%$ of the state's AP/Honors mathematics course participants were low-income students, $23.3 \%$ of the state's AP/Honors science course participants were low-income students, and $25.7 \%$ of the state's AP/Honors social studies course participants were low-income students. In contrast, non low-income students accounted for $69.4 \%$ of the AP/Honors English course participants, $80.7 \%$ of the AP/Honors mathematics course participants, 76.7 of the AP/Honors science course participants, and $74.3 \%$ of the AP/Honors social studies course participants. Just as lowincome students were underrepresented in AP/Honors courses, they were overrepresented in low-track classes across all four content areas studied (English, mathematics, science, and social studies). And as non low-income students were overrepresented in AP/Honors courses, they were underrepresented in low-track courses across the same four content areas.

Tracking policies and practices also disproportionately affected Illinois public high school students based upon race. Black students, for example, made up $17.1 \%$ of the total student population in Illinois, but represented only $12.3 \%$ of the total AP/Honors English course participants, $6.2 \%$ of the total AP/Honors mathematics course participants, $7.4 \%$ of the total AP/Honors science course participants, and $10.0 \%$ of the total AP/Honors social studies course participants. Among low-track courses, Black 
students accounted for $18.1 \%$ of the total participants in English, $19.1 \%$ of the total participants in mathematics, $18.8 \%$ of the total participants in science, and $19.6 \%$ of the total participants in social studies.

Latino students were similarly underrepresented in AP/Honors courses and overrepresented in low-track courses. While Latino students made up $20.2 \%$ of the total student population in Illinois, they accounted for only $19.1 \%$ of the total AP/Honors English course participants, $13.0 \%$ of the total AP/Honors mathematics course participants, $15.4 \%$ of the total AP/Honors science course participants, and $17.1 \%$ of the total AP/Honors social studies course participants. Among low-track courses, Latino students accounted for $20.5 \%$ of the total participants in English, $21.5 \%$ of the total participants in mathematics, $21.0 \%$ of the total participants in science, and $21.3 \%$ of the total participants in social studies.

This study confirms that AP/Honors English, mathematics, science, and social studies courses in Illinois public high schools contain disproportionately low percentages of low-income and minority children, while low-track classes across the same content areas contain disproportionately high percentages of low-income and minority children. Furthermore, by analyzing student performance on the ACT, this study validated the benefits of participating in AP/Honors courses. Across all four content areas studied (English, mathematics, science, social studies/reading), students who participated in AP/Honors courses performed significantly better on ACT tests than students who completed only lower track classes. And, when studying all Illinois public high school students, participation in AP/Honors courses produced a medium treatment effect in English, science, and social studies and a large treatment effect in mathematics. Similar 
treatment effects were observed when students were compared to similar peers, indicating that low-income and minority students benefit from participation in AP/Honors courses. The observed effect sizes suggest that participation in AP/Honors courses is important in all students' educational outcomes and, thus, increasing student exposure to AP/Honors courses will likely improve ACT scores in English, mathematics, science, and reading. It would, therefore, behoove Illinois public high schools to move toward increasing the number of students who participate in AP/Honors courses while simultaneously decreasing the number of students who participate in low-track courses. Consistent with the theoretical framework, the findings of this study suggests increasing exposure to the most rigorous curricular and instructional offerings enable students to perform at higher levels of academic proficiency. So, by making AP/Honors courses available to more students, schools will likely increase the academic performance of their entire population. To this end, the elimination of tracking policies and practices appears advantageous for all students. A deeper analysis of the data obtained through this study, however, suggests that detracking alone will not eliminate the gaps in academic achievement that adversely affect low-income and minority students.

To illustrate this concern, consider the English ACT test performance of Black students. Those who participated in AP/Honors English courses obtained a mean score of 20.61 on the English ACT test. Their performance was significantly better than the 14.91 mean score of Black students who completed only lower track English courses. With a medium treatment effect of approximately $12 \%$, it can be concluded that participation in AP/Honors English courses benefits Black students. When the academic performance of said students is compared to that of White students, however, there is cause for concern. 
As it turns out, White students who participated in only lower track English courses obtained a mean score of 20.32 on the English ACT test. In other words, the performance of White students in low-track courses was comparable to that of Black students who participated in AP/Honors courses. When White students participated in AP/Honors English courses, their mean score increased to 27.93, a full seven points higher than that of Black students in AP/Honors courses. Similar trends were visible across content areas and when Latino students were compared to White students and lowincome students were compared to non low-income students.

These findings suggest that inequity in educational opportunities is not simply limited to access to the most rigorous courses. Instead, it appears that the construct of traditional schooling, including the design of courses, may be particularly advantageous to select student groups. An examination of the mean differences between students who participated in AP/Honors courses and those who did not lends further support to this argument.

Table 29

Mean Differences Between Students Who Participated in AP/Honors Courses and Those Who Did Not (Compared by Race)

\begin{tabular}{lccc}
\hline & Black & Latino & White \\
\hline English & 5.70 & 5.63 & 7.61 \\
Mathematics & 5.58 & 6.63 & 8.63 \\
Science & 4.46 & 4.69 & 6.16 \\
Reading & 4.40 & 4.89 & 5.91 \\
\hline
\end{tabular}


As depicted in Table 29, the mean difference in English ACT test performance between Black students who participated in AP/Honors English courses and those who did not was 5.70. Among Latino students, the mean difference in English ACT test performance between those who participated in AP/Honors English courses and those who did not was a comparable 5.63. The mean difference in English ACT test performance between White students who participated in AP/Honors English courses and White students who only completed lower-track courses, however, was a much higher 7.61. Indeed, across all four content areas studies (English, mathematics, science, social studies/reading), mean differences between students who completed AP/Honors courses and those who did not were considerably higher among White students when compared to Black and Latino students. These higher mean differences indicate that, while all students benefit from participation in AP/Honors courses, White students derive a greater benefit from participating in these courses than their Black and Latino counterparts.

As demonstrated in Table 30, similar trends were apparent when low-income students were compared to non low-income students.

Table 30

Mean Differences Between Students Who Participated in AP/Honors Courses and Those Who Did Not (Compared by Socioeconomic Status)

\begin{tabular}{lcc}
\hline & Low-Income & Non Low-Income \\
\hline English & 5.63 & 7.44 \\
Mathematics & 6.77 & 8.59 \\
Science & 5.05 & 6.03 \\
Reading & 4.57 & 5.84 \\
\hline
\end{tabular}


Again, with higher mean differences, non low-income students appear to derive a greater benefit than low-income students from participation in AP/Honors courses. This being the case, the Black/White, Latino/White, and low-income/non low-income achievement gaps cannot be eliminated by merely equalizing participation in the courses deemed most rigorous by traditional schools. Rather, the findings of this study suggest that the design of these courses within the traditional construct of schooling benefits White and non lowincome children and, therefore, an attempt to increase rigor within the current system augments this effect. In other words, if Illinois public high schools were to simply eliminate tracking policies and practices, the academic performance of all students would likely increase, but gaps in academic achievement would continue to grow because the performance of White students would increase more substantially than that of Black and Latino students, and the performance of non low-income students would increase more substantially than that of low-income students.

\section{Implications for Further Research}

Had Black and Latino students who participated in AP/Honors courses performed comparably to White students participating in the same courses, it could be concluded that eliminating race-based achievement gaps is a mere matter of providing all students with equal access to the most rigorous courses. Similarly, had low-income AP/Honors course participants performed comparably to their non low-income peers in these same courses, achievement gaps based upon socioeconomic status could be closed through detracking reform efforts alone. This was not the case across the state of Illinois. In fact, the educational benefits of AP/Honors course participation were found to be most advantageous for two groups historically privileged under the construct of traditional 
American schooling-White and non low-income students.

To be clear, the benefits of participation in AP/Honors courses was statistically significant for all students, regardless of race, socioeconomic status, and content area. When properly supported, all students stand to benefit from increased opportunities to participate in the school's most rigorous courses. Increasing the number of students who participate in $\mathrm{AP} /$ Honors courses is a critical step in the pursuit of achievement equity. Based upon the findings of this study, however, detracking must be a part of a larger plan to transform the traditional construct of schooling. To this end, several recommendations for further study emerged:

1. This study examined the relationship and differences between students who have completed AP/Honors courses and those who have not in traditional Illinois public high schools. Future studies should be conducted to examine similar relationships among students attending public schools in states throughout the nation, as well as, students attending private schools in Illinois and across the country. Indeed, there are a number of private Illinois high schools that remain effectively detracked as a result of limited enrollment, staff, and course offerings.

2. While this study examined student data for all Illinois public high school students who completed the ACT during the 2012-2013 school year, the study was limited to only one year of data collection. This approach is substantial for identifying problems, but fails to assess trends toward correcting said problems. Future studies should include a multiyear approach to data analysis in order to determine the extent to which the problem is either aggravated or mitigated over time. 
3. The academic achievement of students examined for this study was measured by the nationally-normed ACT assessment. While this assessment is generally accepted as valid and reliable across the United States and throughout the world, it represents only one potential educational outcome that can be measured. Future studies should examine the relationship and differences between students who have completed AP/Honors courses and those who have not in relation to other measures of educational outcomes, including, but not limited to, SAT performance, high school grade-point-average (GPA), high school graduation rate, college enrollment rates, performance on college entrance exams, and college graduation rates.

4. The findings of this study suggest that detracking reform efforts alone will not eliminate achievement gaps based upon socioeconomic status and race. It can be concluded that factors beyond equal access to the school's most rigorous curriculum and instruction affect students' educational outcomes. Further research is needed to identify and examine these factors. Schools in which low-income and minority students performed comparably to non low-income and White students on measures of educational outcomes (e.g., ACT performance) should be studied with the intention of understanding how curriculum and instruction in these schools differ from that offered in a traditional school.

\section{Summary and Conclusions}

Supported by the theoretical framework and the findings of this study, providing every child with equal educational opportunities, including exposure to a rigorous curriculum and uniform quality of instruction, will improve educational outcomes for all students. In public high schools across the state of Illinios, low-income and minority 
students performed significantly better on the ACT than similar peers when they had the opportunity to participate in AP/Honors courses. And because these courses are generally considered the most rigorous courses offered, it can be concluded that higher levels of academic achievement follow from more meaningful educational opportunities.

While participation in AP/Honors courses benefited low-income and minority students, the findings of this study also demonstrated that the derived benefits were not equal to the advantages that non low-income and White students experienced when they participated in the same courses. This reality presents a complex challenge for schools aspiring to not only improve educational outcomes but also close gaps in academic achievement between various student groups. Since the elimination of tracking policies and practices alone will not sufficiently eliminate achievement gaps based upon socioeconomic status and race, a more comprehensive understanding of what detracking truly requires is needed. To this end, educators must recognize the important distinction between educational "reform" and "transformation."

In the context of school improvement, reform generally entails changing procedures, processes, and technologies with the intent of improving the performance of existing operating systems. In other words, reform is aimed at making existing systems more effective at doing what they have always done. For example, if low-track classes are eliminated and all students are afforded equal opportunities to experience the most rigorous courses, then student performance will likely increase. Under this scenario, the existing system becomes more effective in a manner consistent with the definition of educational reform. The reform effort does not, however, eliminate the gaps in academic achievement that already exist as a result of the traditional system of schooling. 
Accepting that the system itself may perpetuate achievement inequity allows educators to embrace educational transformation rather than settle for reform. Unlike reform, transformation involves repositioning and reorienting action through the adoption of radically different means of doing the work it has traditionally done. Whereas reform seeks to install initiatives that will work within the context of the existing structure and culture of schools, transformation necessitates altering the social structure and culture to support the needed change (Schlechty, 2009).

Many seeking transformational change in education have made a case that traditional schools are not intentionally organized to empower all students to achieve at high levels (Schlechty, 2009; Delpit, 2012; Sims, 2008). In support of this argument, it is contended that the American interpretation of schooling has been derived almost exclusively from the classical and popular cultural formations of the dominant society. In other words, traditional school culture is and always has been that of White middle class America (Delpit, 2012).

The findings of this study lend support to the argument that traditional construct of schooling favors the cultural formations of the dominant society. Not only were lowincome and minority students overrepresented in low-track courses and underrepresented in high-track courses, but when these students were provided the opportunity to participate in more rigorous courses, their resulting achievement gains were not as substantial as those experienced by non low-income and White students in the same courses. The fact that the courses most revered under the current construct of schooling did more to benefit non low-income and White students than they did to benefit lowincome and Black and Latino students suggests that equality in educational opportunities 
is not limited to the access of particular courses, but also how curriculum and instruction are delivered within these courses.

Accordingly, any effort to detrack America's schools must extend well beyond reforming students' access to the courses traditionally considered to be the most rigorous. Rather, detracking in pursuit of achievement equity requires attention to the curriculum and instruction delivered in an environment of equal access. This approach to detracking necessitates transformative action and requires educators to undergo philosophical and pedagogical shifts in their thinking and practice.

To pursue detracking as a means of realizing achievement equity, educators must recognize that low-income and minority students are marginalized as a result of traditional schooling practices. They cannot continue to allow the cultural formations of the students they serve to influence their judgments about the intellectual capabilities of these children, particularly those from low-income and minority families. Further, they must challenge traditionally accepted notion of "rigorous" curriculum and instruction in favor of a more inclusive and culturally responsive approach to education.

Culture can be defined as the lens through which people interpret life events (Boykin \& Noguera, 2011). Culture includes the learned behaviors, orientations, interpersonal patterns, beliefs, values, and underlying assumptions that are prevalent among the members of a society. Culturally competent educators recognize the connection between culture and learning. While teaching, they consistently demonstrate an awareness and sensitivity of the cultural knowledge, beliefs, and practices that students bring into the classroom. In doing so, they remain responsive to the culturerelated inclinations of the students they serve. Due to the diverse nature of America's 
classrooms, detracking in pursuit of achievement equity requires attention to culturally responsive pedagogy.

According to Howard (2010),

Culturally responsive pedagogy assumes that if teachers are able to make connections between the cultural knowledge, beliefs, and practices that students bring from home, and the content and pedagogy that they use in their classrooms, the academic performance and overall schooling experiences of learners from culturally diverse groups will improve. (pp. 67-69)

In a detracked classroom, educators must incorporate diverse cultural inclinations into teaching and learning contexts, so students, particularly those traditionally marginalized under the traditional system of schooling, are more likely to remain engaged throughout the learning process.

Teaching in a detracked classroom is certainly different, and arguably more challenging, than teaching in a traditional classroom where the educator's responsibility is to teach to a specific performance level and acclimate students to a particular culture. As indicated by the findings of this study, however, such transformation is necessary if all students are to perform at the high levels of proficiency expected under the No Child Left Behind Act and Common Core State Standards. Providing all students with equal opportunities to participate in rigorous courses will likely improve the academic achievement of all children. But because such improvement does not in and of itself translate to a narrowing of achievement gaps based upon socioeconomic status and race, the findings of this study also suggest that attention to culturally responsive pedagogy is necessary. More specifically, educators must begin to recognize the valuable contributions that all students, including low-income and minority children, bring into the classroom and use this knowledge to create equitable opportunities for all children to 
succeed in school and life. Among these opportunities is access to a rigorous curriculum and uniform quality of instruction that reflect the cultural inclinations of a pluralistic society. Detracking America's classrooms in this manner will require educators to challenge the traditional assumptions of learning and schooling that have adversely affected low-income and minority students for far too long. Through truly equal opportunities, achievement equity can become a reality for all children. 


\section{REFERENCES}

ACT. (2013). Retrieved September 3, 2013, from http://www.act.org.

Alvarez, D., \& Mehan, H. (2006). Whole-school detracking: A strategy for equity and excellence. Theory into Practice, 45(1), 82-89.

Anyon, J. (2005). Racial possibilities: Public policy, urban education, and a new social movement. New York: Routledge.

Ascher, C. (1992). Successful detracking in middle and senior high schools. ERIC Clearinghouse on Urban Education, 82.

Baum, W. M. (1994). Understanding behaviorism: Science, behavior, and culture. New York: Harper Collins College Publishers.

Boaler, J. (2006). How a detracked mathematics approach promoted respect, responsibility, and high achievement. Theory into Practice, 45(1), 40-46.

Bobbitt, F. (1913). The twelfth yearbook of the National Society for the Study of Education: The supervision of city schools. Chicago, IL: The University of Chicago Press.

Boykin, A. W. \& Noguera, P. (2011). Creating the opportunity to learn: Moving from research to practice to close the achievement gap. Alexandria, VA: Association for Supervision and Curriculum Development.

Braddock, J. (1990). Tracking the middle grades: National patterns of grouping for instruction. Phi Delta Kappan, 71(6), 445-449.

Bruner, J. (1986). Actual minds, possible worlds. Cambridge, MA: Harvard University Press.

Burris, C. C., \& Garrity, D. T. (2008). Detracking for excellence and equity. Alexandria, VA: Association for Supervision and Curriculum Development.

Burris, C. C., \& Welner, K. G. (2005). Closing the achievement gap by detracking. Phi Delta Kappan, 594-598.

Callahan, R. E. (1962). Education and the cult of efficiency. Chicago: University of Chicago Press. 
Cicourel, A. \& Mehan, H. (1985). Universal development, stratifying practices and status attainment. Social Stratification and Mobility, 4, 3-27.

Cohen, J. (1988). Statistical power analysis for behavioral sciences. Hillsdale, NJ: Lawrence Erlbaum Associates.

Conley, D. T. (2007). Toward a more comprehensive conception of college readiness. Retrieved November 9, 2009, from http://www.gatesfoundation.org/learning/Documents/CollegeReadinessPaper.pdf

Cooper, E. \& Sherk, J. (1989). Addressing urban school reform: Issues and alliances. Journal of Negro Education, 58(3), 315-331.

Cubberly, E. P. (1909). Changing conceptualizations of education. Boston, MA: Houghton Mifflin.

Cremin, L. A. (1964). The transformation of the school. New York, NY: Random House.

Creswell, J.W. (2009). Research design: Qualitative, quantitative, and mixed methods approaches. Thousands Oakes, CA: Sage Publications, Inc.

Darling-Hammond, L. (2010). The flat world and education: How America's commitment to equity will determine our future. New York, NY: Teachers College Press.

Delpit, L. (2012). Multiplication is for white people: Raising expectations for other people's children. New York: The New Press.

Dewey, J. (1897). My pedagogic creed. School Journal, 54, 77-80.

Dornbusch, S.M. (1994). Off the track. Presidential address to the Society for Research on Adolescence, San Diego, CA.

DuFour, R. \& Eaker, R. (1998). Professional learning communities at work: Best practices for enhancing student achievement. Bloomington, IN: Solution Tree Press.

Dweck, C. (2006). Mindset: The new psychology of success. New York, NY: Ballantine Books.

Eckstrom, R. \& Villegas, A. (1991). Ability grouping in middle grade mathematics: Process and consequences. Research in Middle Level Education, 15(1), 1-20.

Edmonds, R.E. (1979). Effective schools for the urban poor. Educational Leadership, $36(10), 15-23$. 
Eliot, C. W. (1898). Educational reform essays and addresses. New York, NY: The Century Company.

Elmore, R. (2002). Bridging the gap between standards and achievement: The imperative for professional development in education. Washington, DC: The Albert Shanker Institute.

Friedman, T. L. (2007). The world is flat: A brief history of the twenty-first century. New York, NY: Picador.

Garoman, A. (1989). Measuring curriculum differentiation. American Journal of Education, 97(2), 129-143.

Garoman, A. (1987). The stratification of high school learning opportunities. Sociology of Education, 60(3), 135-155.

Garoman, A. \& Mare, R. (1989). Secondary school tracking and educational inequality: Compensation, reinforcement, or neutrality? American Journal of Sociology, 94(5), 1146-1183.

George, P. (1993). Tracking and ability grouping in middle school: Ten tentative truths. Middle School Journal, 24(4), 17-24.

Goodman, K. S., Shannon, P., Freeman, S. Y., \& Murphy, S. (1988). Report card on basal readers. Katonah, NY: Richard C. Owen Publishers, Inc.

Gravetter, F. J. \& Wallnau, L. B. (2007). Statistics for the behavioral sciences. Belmont, CA: Thomson Wadsworth.

Hallinan, M., \& Williams, R. A. (1990). Students' characteristics and the peer-influence process. Sociology of Education, 63(2), 122-132.

Hattie, J. (2009). Visible learning: A synthesis of over 800 meta-analyses relating to achievement. New York, NY: Routledge.

Howard, T. C. (2010). Why race and culture matters in schools: Closing the achievement gap in America's classrooms. New York, NY: Teachers College Press.

Jencks, C., Smith, M., Aclanand, H., Bane, M., Cohen, D., Gintis, H., Heyns, B., \& Michelson, S. (1972). Inequality: A reassessment of the effect of family and schooling in America. New York, NY: Basic Books.

Jencks, C. \& Phillips, M. (1998). The Black-White test score gap. Washington, DC: The Brookings Institution. 
Kelly, F. S., McCain, T, \& Jukes, I. (2009). Teaching the digital generation: No more cookie-cutter high schools. Thousand Oaks, CA: Corwin Press.

Kunjufu, J. (1995). Countering the conspiracy to destroy black boys. Chicago, IL: African American Images.

Kunjufu, J. (2002). Black students-middle-class teachers. Chicago, IL: African American Images.

Lambert, L., Walker, D., Zimmerman, D. P., Cooper, J. E., Lambert, M. D., Gardner, M. E., Szabo, M. (2002). The constructivist leader. New York, NY: Teachers College Press.

Levin, H. M. \& Rouse, C. E. (2011, January 26). The true cost of high school dropouts. The New York Times, p. A23.

Lucas, S. (1999). Tracking inequalities. New York, NY: Teachers College Press.

Marzano, R. J. (2000). A new era of school reform: Going where the research takes us. Aurora, CO: Mid-continent Research for Education and Learning. Retrieved September 3, 2013, from http:/qualitylearning.net/community/brownsville/ research/A\%20New\%20Era\%20of\%20School\%20Reform.pdf.

Meier, D. (1995). The power of their ideas: Lessons from a small school in Harlem. Boston, MA: Beacon Press.

Muhammad, A. (2009). Transforming school culture: How to overcome staff division. Bloomington, IN: Solution Tree Press.

National Center for Education Statistics. (2013). Retrieved July 11, 2013, from http://nces.ed.gov/nationsreportcard/.

No Child Left Behind Act of 2001, 20 U.S.C. 6319 (2008).

Oakes, J. (1992). Can tracking research inform practice? Technical, normative, and political considerations. Educational Researcher, 12-21.

Oakes, J. (2005). Keeping track: How schools structure inequality. New Haven, CT: Yale University Press.

Oakes, J., Gamoran, A., \& Page, R. (1992). Curriculum differentiation: Opportunities, outcomes, and meanings. Handbook of Research on Curriculum. New York, NY: Macmillan, 570-608.

Oakes, J. \& Wells, A. (1998). Detracking for high achievement. Educational Leadership, $55(6), 38-41$. 
Organization for Economic Cooperation and Development. (2013). Retrieved October 2, 2013, from http://www.oecd.org/pisa/aboutpisa/

Pillsbury, W. B. (January, 1921). Selection: An unnoticed function of education. The Scientific Monthly. 12(1), 62-74.

Reardon, S. F. (2011). The widening academic achievement gap between the rich and the poor: New evidence and possible explanations. In R. Murnane \& G. Duncan (Eds.), Whither Opportunity? Rising Inequality and the Uncertain Life Chances of Low-Income Children. New York, NY: Russell Sage Foundation Press. Retrieved October 24, 2013, from http://cepa.stanford.edu/content/widening-academicachievement-gap-between-rich-and-poor-new-evidence-andpossible\#sthash.3ug6VF1L.dpuf.

Rees, J. (2001). Frederick Taylor in the classroom: Standardized testing and scientific management. Radical Pedagogy, 3(2). Retrieved March 10, 2013, from http://www.radicalpedagogy.org/Radical_Pedagogy/Frederick_Taylor_In_The_Cl assroom_Standardized_Testing_And_Scientific_Management.html

Resnick, L. (1995). From aptitude to effort: A new foundation for our schools. Daedalus. 12(4), 55-62.

Rosenbaum, J. E. (1999). If tracking is bad, is detracking better. American Educator, Winter 1999-2000, 1-7.

Rothstein, R. (2004). Class and schools: Using social, economic, and educational reform to close the Black-White achievement gap. New York, NY: Teachers College Press.

Rubin, B. (2006). Tracking and detracking: Debates, evidence, and best practices for a heterogeneous world. Theory into Practice, 45(1), 4-14.

Schlechty, P. C. (2009). Leading for learning: How to transform schools into learning organizations. San Francisco, CA: Jossey-Bass.

Senge, P. M. (1990). Give me a lever long enough... and single-handed I can move the world. In The Jossey-Bass reader on educational leadership (pp. 13-25). San Francisco, CA: Jossey-Bass.

Senge, P., Cambron-McCabe, N., Lucas, T., Smith, B., Dutton, J., \& Kleiner, A. (2012). Schools that learn: A fifth discipline fieldbook for educators, parents, and everyone who cares about education. New York, NY: Crown Business.

Shafer, W. E., \& Olexa, C. (1971). Tracking and opportunity. Scranton, PA: Chandler. 
Shepard, L. A. (2000). The role of assessment in a learning culture. Educational Researcher (29)7, 4-14.

Sims, D. J. (2008). Hardwired by nature: What we as educators underestimate about our minority students. Lexington, KY: Xlibris Corporation.

Sirin, S. R. (2005). Socioeconomic status and academic achievement: A meta-analytic review of research. Review of Educational Research. 75(3), 417-453.

Skinner, B. F. (1968). The technology of teaching. New York, NY: Appleton Century Crofts.

Symonds, W. C., Schwartz, R. B., \& Ferguson, R. (2011). Pathways to prosperity: Meeting the challenge of preparing young Americans for the 21st century. Report issued by the Pathways to Prosperity Project, Harvard Graduate School of Education.

Taylor, F. W. (1911). Shop management. New York, NY: Harper \& Brothers Publishing.

Trilling, B., \& Fadel, C. (2009). $21^{\text {st }}$ century skills: Learning for life in our times. San Francisco, CA: Jossey-Bass.

U.S. Department of Education. (2010). A blueprint for reform: The reauthorization of the Elementary and Secondary Education Act. Washington, DC: U.S. Department of Education.

Wagner, T. (2008). The global achievement gap: Why even our best schools don't teach the new survival skills our children need-and what we can do about it. New York, NY: Basic Books.

Wells, A. S., \& Oakes, J. (1996). Potential pitfalls of systemic reform: Early lessons from research on detracking. Sociology of Education (special issue), 135-143.

Wells, A. S. \& Serna, I. (1996). The politics of culture: Understanding local political resistance to detracking in racially mixed schools. Harvard Educational Review, 66(1), 93-118.

Welner, K., \& Oakes, J. (1995, April). Liability grouping: The new susceptibility of school tracking systems to legal challenges. Paper presented at the annual meeting of the American Educational Research Association, San Francisco.

White, K. R. (May 1982). The relationship between socioeconomic status and academic achievement. Psychological Bulletin. 91(3), 461-481. 
Wilson, W. J. (2009). More than just race: Being Black and poor in the inner city. New York, NY: Norton.

Yonezawa, S., \& Jones, M. (2006). Students' perspectives on tracking and detracking. Theory into Practice, 45(1), 15-23.

Yonezawa, S., Wells, A. S., \& Serna, I. (2002). Choosing tracks: Freedom of choice in detracking schools. American Educational Research Journal, 39(1), 37-67. 